\title{
Geochemical - geology characteristics implicating original sources and copper - deposit type in Kon Ra ore - field
}

\author{
Niem Van Nguyen ${ }^{1,}$, Dung Tien Nguyen ${ }^{2}$, Duan Tran ${ }^{2}$, Tu Trong Mai ${ }^{3}$, Nguyen \\ Duc Do ${ }^{1}$, Hieu Cong Duong ${ }^{1}$, Viet Huu Bui ${ }^{1}$ Thanh Hung Pham ${ }^{1}$ \\ 1 Vietnam Institute of Sciences and Mineral Resources, Hanoi, Vietnam \\ ${ }^{2}$ South Vietnam Geological Mapping Division, Ho Chi Minh Gity, Vietnam \\ ${ }^{3}$ General Department of Geology and Minerals in Viet Nam, Hanoi, Vietnam
}

ARTICLE INFO

Article history:

Received $18^{\text {th }}$ May 2021

Revised 29th Aug. 2021

Accepted 29 $9^{\text {th }}$ Sept. 2021

Keywords:

Cooper deposit type.

Geochemistry - geology,

Kon Ra,

Skarnoid.
ABSTRACT

Based on the research results on petrographic - mineralogical characteristics, tectonic structural features, geochemistry of major and trace elements of the bedrock, alternative rock, ore, soil, mineralogical geochemistry, mineral facies, inclusions, the origin of ore formation related to oxidized granite and skarnoid - typed metasomatic process in Kon Ra copper ore field have been identified. Petrological and mineral characteristics indicate the process of transitional metasomatism between the skarn and hornfels, also known as bimetasomatic stage (skarnoid deposit type). Diopxite represents the Progade skarnoid stage. Tremolite, actinolite, quartz, chlorite, magnetite, molybdenite, less of chalcopyrite, pyrrhotite, and pyrite indicate the retrogade skarnoid stage. The following is sulfide - quartz stage (major minerals include: quartz, chalcopyrite, pyrite, pyrrhotite, molybdenite). This result is also consistent with the formation temperature $210 \div 270{ }^{\circ} \mathrm{C}$ and the geochemical zoning of elements from intrusive blocks through the outer contact zone that contains the ore and surrounding rocks are as follows: $\mathrm{Cu}, \mathrm{Zn}, \mathrm{Ca}$ (the zone has lime-rich formations), $\mathrm{Fe}^{3+}$, Mo increases in the outer contact zone containing ore closed to acid intrusive rocks. Inversely, the ratios of $\mathrm{Pb} / \mathrm{Cu}$, $\mathrm{Zn} / \mathrm{Cu}$, and As content increased in the alteration from this zone to the outer one. In addition, uranium mineralization is associated with a later magma stage (pegmatite granite in endo-contact is high uranium radiation: $U=$ $0.17 \div 0.2 \%, 3,420,000 \div 8,020,000 \mu R / h$ and contains uraninite).

Copyright (C) 2021 Hanoi University of Mining and Geology. All rights reserved.

${ }^{*}$ Corresponding author

E - mail: niemnv78@gmail.com

DOI: 10.46326/JMES.2021.62 (5).02 


\title{
Tạp chí Khoa học Kỹ thuật Mỏ - Địa chất
}

\section{Đặc điểm địa hóa - địa chất chỉ thị nguồn gốc thành tạo kiểu mỏ đồng ở trường quặng Kon Rá}

\author{
Nguyễn Văn Niệm 1, ${ }^{*}$, Nguyễn Tiến Dũng 22, Trần Duân 2, Mai Trọng Tú ${ }^{3}$, Đỗ Đức \\ Nguyên ${ }^{1}$, Dương Công Hiếu ${ }^{1}$, Bùi Hữu Việt ${ }^{1}$, Phạm Hùng Thanh ${ }^{1}$ \\ ${ }^{1}$ Viện Khoa học Địa chất và Khoáng sản, Hà Nội, Việt Nam \\ ${ }^{2}$ Liên đoàn Bản đồ Địa chất miền Nam, TP. Hồ Chí Minh, Việt Nam \\ 3 Tổng Cục Địa chất và Khoáng sản Việt Nam, Hà Nội, Việt Nam
}

\section{THÔNG TIN BÀI BÁO \\ Quá trình: \\ Nhận bài $18 / 5 / 2021$ \\ Sửa xong 29/8/2021 \\ Chấp nhận đăng 29/9/2021}

\section{Tù khóa:}

Đia hoa- đia chat,

Kiểu mo đong,

Kon Rá,

Skarnoid.

\section{TÓM TẮT}

Trên cơ sở kết quả nghiên cứu đặc điểm thạch học - khoáng vật, đặc điểm cấu trúc kiến tạo, địa hóa các nguyên tố chính và nguyên tố vết của đá gốc, đá biến đổi, quặng, đất, địa hóa khoáng vật, khoáng tướng, bao thể đã xác định nguồn gốc thành tạo quặng liên quan với granit có tính oxy hóa và quá trình biến chất trao đổi kiểu skarnoid ở truờng quặng đồng Kon Rá. Đặc điểm thạch học, khoáng vật chỉ thi quá trình biến chất trao đổi chuyển tiếp của skarn và sùng hóa hay còn gọi là giai đoạn biến chất trao đổi trung gian (bimetasomatic stage) - kiểu mỏ skarnoid: diopxit biểu hiện cho giai đoạn skarnoid tiến hóa (progade skarnoid); tremolit, actinolit, thạch anh, chlorit, magnetit, molipdenit, ít hơ là chalcopyrit, pyrotin, pyrit chỉ thi giai đoan skarnoid tiến hóa giật lùi (retrograde skarnoid); tiếp theo là giai đọan sulfua - thạch anh (khoáng vật chính gồm: thạch anh, chacopyrit, pyrit, pyrotin, molipdenit). Kết quả này cũng phù hợp với nhiệt độ thành tạo $210 \div 270{ }^{\circ} \mathrm{C}$ và sự phân đới địa hóa các nguyên tố tù̀ khối xầm nhập qua đới ngoại tiếp xúc chứa quăng và đá vây quanh như sau: $\mathrm{Cu}, \mathrm{Zn}, \mathrm{Ca}$ (khi đới có các thành tạo giàu vôi), $\mathrm{Fe}^{3+}$, Mo tắng ở đới ngoại tiếp xúc chứa quặng gần đá xâm nhập acid; ngược lại, biến thiên tù đới này ra phía ngoài, tỷ số $\mathrm{Pb} / \mathrm{Cu}, \mathrm{Zn} / \mathrm{Cu}$ và hàm lượng As tăng. Ngoài ra, biểu hiện khoáng hóa urani liên quan đến giai đoạn magma muộn hơ (granit pegmatit đới nội tiếp xúc, cao $U=$

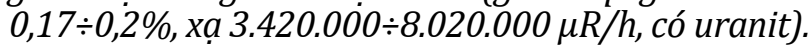

(C) 2021 Trường Đại học Mỏ - Địa chất. Tất cả các quyền được bảo đảm.

\section{Mở đầu}

Trường quặng Kon Rá có diện tích khoảng

*Tác giả liên hệ

E - mail: niemnv78@gmail.com

DOI: 10.46326/JMES.2021.62 (5).02 gần $30 \mathrm{~km}^{2}$, kéo dài dọc theo hệ thống đứt gãy phương bắc đông bắc - nam tây nam, thuộc huyện Kon Rẫy, Kon Tum (Hình 1). Quặng hóa đồng phân bố trong đới dập vỡ kiến tạo và đới biến đổi ngoại tiếp xúc của đá biến chất cổ tuổi Proterozoi, chúng đi cùng khoáng hóa urani và molybden, sắt. Trên mặt, lộ ra vài thân quặng đồng; phần ẩn sâu còn 


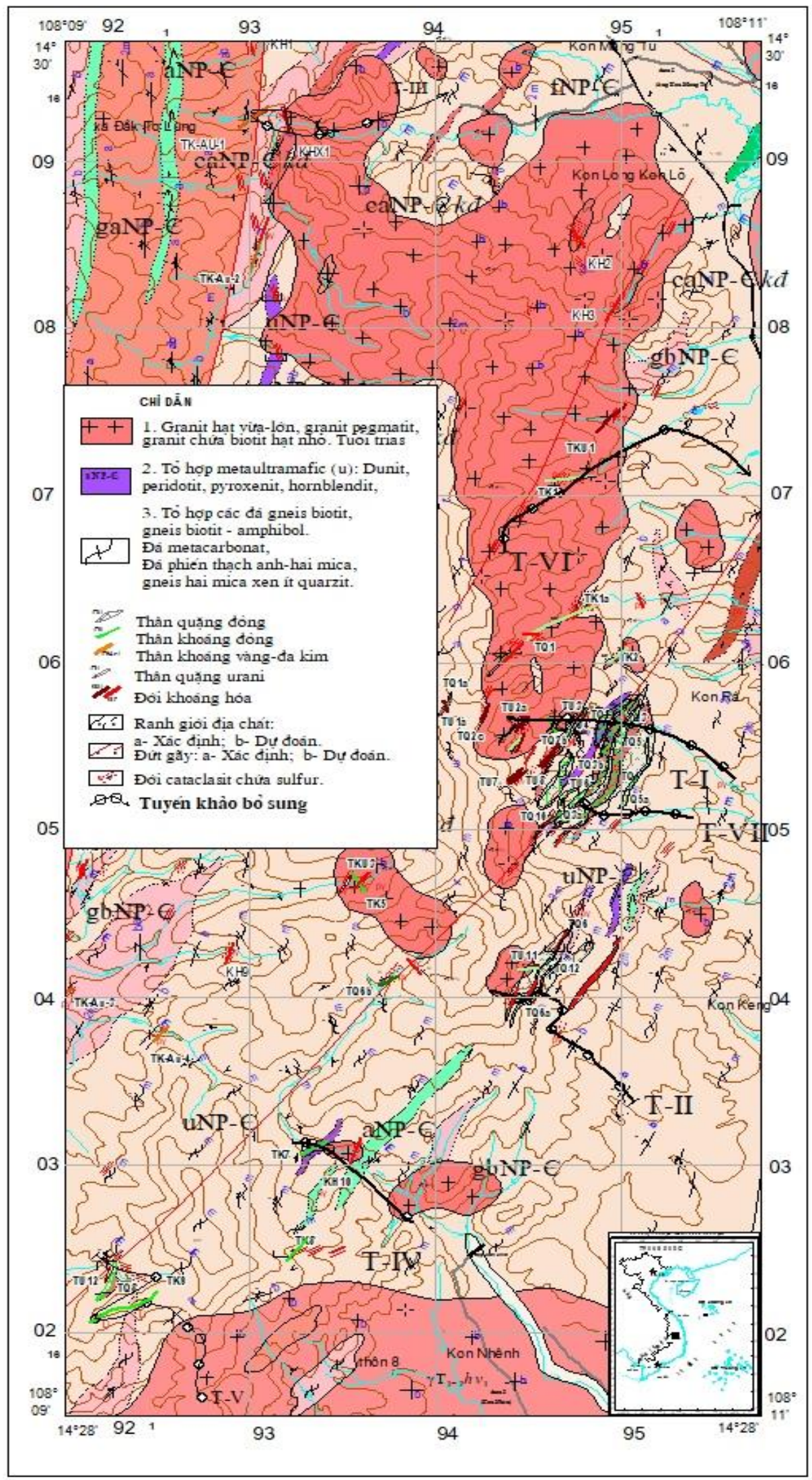

Hình 1. So đồ khu vực nghiên cúu và các tuyến lấy mẫu bổ sung (T - IV: Các tuyến; CD: Mặt cắt). 
gặp khoáng hóa của molybden, urani nhưng có thể là các giai đoạn tạo khoáng khác nhau. Đặc biệt, uraninit và các khoáng vật thứ sinh của nó (đới xạ rất cao) cùng molybdenit xuất hiện ngay trong đới nội tiếp xúc của granit pegmatit.

Về mặt không gian, các thân quặng, mạch quặng phân bố không đều và khá gần đến sát các khối granit tuổi Trias cùng một số mạch felsit tuổi Jura. Ngoài ra, còn gặp nhiều khối granit nhỏ lân cận trường quặng.

Trong cấu trúc trường quặng khá phức tạp về các tổ hợp đá, sự phân bố các thể magma ở trên mặt và dưới sâu, các thành phần đá biến đổi không đồng nhất. Vì thế, việc xác định kiểu mỏ dựa trên thành phần vật chất kết hợp với cấu trúc địa chất của trường quặng này chưa rõ ràng. Để giải quyết vấn đề này, nghiên cứu này đã sử dụng các tham số địa hóa kết hợp với đặc điểm thạch học, khoáng tướng, bao thể, đồng vị, đơn khoáng theo không gian và thời gian của nền cấu trúc địa chất trường quặng.

\section{Dữ liệu và phương pháp nghiên cứu}

Nguồn tài liệu được nghiên cứu bao gồm các mẫu lát mỏng thạch học, khoáng tướng, bao thể, các mẫu địa hóa của đá gốc, đất, đới biến đổi, quặng được nghiên cứu theo không gian (các tuyến từ trung tâm thân quặng ra đới biến đối, đá gốc vây quanh; tính cả quan hệ theo độ sâu) và theo thời gian (các thế hệ quặng, các kiểu đá có thời gian thành tạo khác nhau). Để có nguồn dữ liệu hệ thống này, tập thể tác giả đã khảo sát thực địa và xây dựng các tuyến lấy mẫu đại diện cho từng đối tượng cụ thể (trên cơ sở nghiên cứu, kế thừa kết quả thạch học, khoáng tướng, $\mathrm{AAS}$, silicat lấy trong 9 lỗ khoan và các hào địa chất trước đây để chọn lọc, bổ sung mẫu). Đồng thời, nghiên cứu tổng quan về địa chất, cấu trúc khu vực, các giai đoạn biến chất và đá nguyên thủy; lấy bổ sung mấu chuẩn trên 8 tuyến như Hình 1 (theo tập mẫu đồng bộ: thạch học, khoáng tướng, địa hóa, bao thể, đo xạ và phổ).

Các phương pháp phân tích thành phần vật chất và xử lý kết quả gồm: đồng hóa bao thể (xác định nhiệt độ thành tạo), thạch học (đặc điểm thành phần khoáng tạo đá, các quá trình biến đổi), khoáng tướng (phát hiện các khoáng vật quặng, thứ tự thành tạo), silicat (6 mẫu), ICP (32 mẫu: nghiên cứu tính phân đới kim loại) và ICP - MS (11 mẫu, xác định thành phần các nguyên tố làm cơ sở nghiên cứu quy luật phân bố, điều kiện và nguồn gốc tạo quặng, khả năng sinh kim của đá gốc, quá trình biến đổi, môi trường địa hóa hệ magma quặng,...), EDS phân tích thành phần nguyên tố trong khoáng vật để luận giải nguồn gốc các quá trình tạo quặng.

\section{Kết quả và thảo luận}

\section{1. Đặc điểm địa chất, cấu trúc khu vực Kon Rá}

Trường quặng Kon Rá có cấu trúc của một vòm xâm nhập granit gồm các khối xâm nhập granit, granit pegmatit (tuổi trias) và các đai mạch aplit, các mạch nhiệt dịch đi kèm, chúng phân bố dọc theo đới đứt gãy đông bắc - tây nam.

Phía bắc trường quặng có mặt của đứt gãy á kinh tuyến, tạo nên đới vò nhàu, uốn nếp rộng ít nhất vài trăm mét. Đới đứt gãy phương đông bắc tây nam thuận lợi cho tập trung quặng đồng urani và khoáng sản đi kèm.

Các đá granit gây biến chất trao đối với các thành tạo đá biến chất cổ, cụ thể: i) granit hạt nhỏ, hạt vừa - lớn trong khu vực nghiên cứu (trước đây xếp vào phức hệ Hải Vân), các kiểu đá granit ở đây chưa phát hiện được sự phân pha; ii) đá vây quanh là đá biến chất thuộc hệ tầng Tắc Pỏ (PR tp) giàu carbonat, dolomit, chứa graphit (Trần Duân ghép thành phức hệ Khâm Đức). Nguồn gốc nguyên thủy của đá biến chất này gồm đá phiến sét, greywack, đá vôi và dolomit, mamga (Trần Duân, 2021) (Hình 2).

Quá trình biến chất các đá gneis biotit hornblen ở khu vực nghiên cứu thuộc giai đoạn trias $(227 \div 236 \pm 1$ tr.n.). Tương tự, khu vực Khâm Đức các đá cũng có tuổi biến chất $227 \div 237 \pm 3$ tr.n. (gneis biotit) và $230 \pm 3$ tr.n. (đá phiến mica) (Nguyễn Xuân Bao, 2000). Hiện nay, vẫn quan sát được một số điểm đá vôi dolomit, đá phiến chứa graphit cạnh bờ sông Đăk Akoi.

\section{2. Đặc điểm thạch học, khoáng vật của đá vây quanh và quặng}

\subsubsection{Granit}

Có hai loại chính: granit chứa ít - rất ít biotit hạt nhỏ, sáng màu; loại granit biotit màu nâu đen (> 5\% biotit). Ngoài ra, còn gặp cả granit pegmatit chứa khoáng vật màu đen của urani đi kèm granit hạt nhỏ chứa molipden (KR109). 

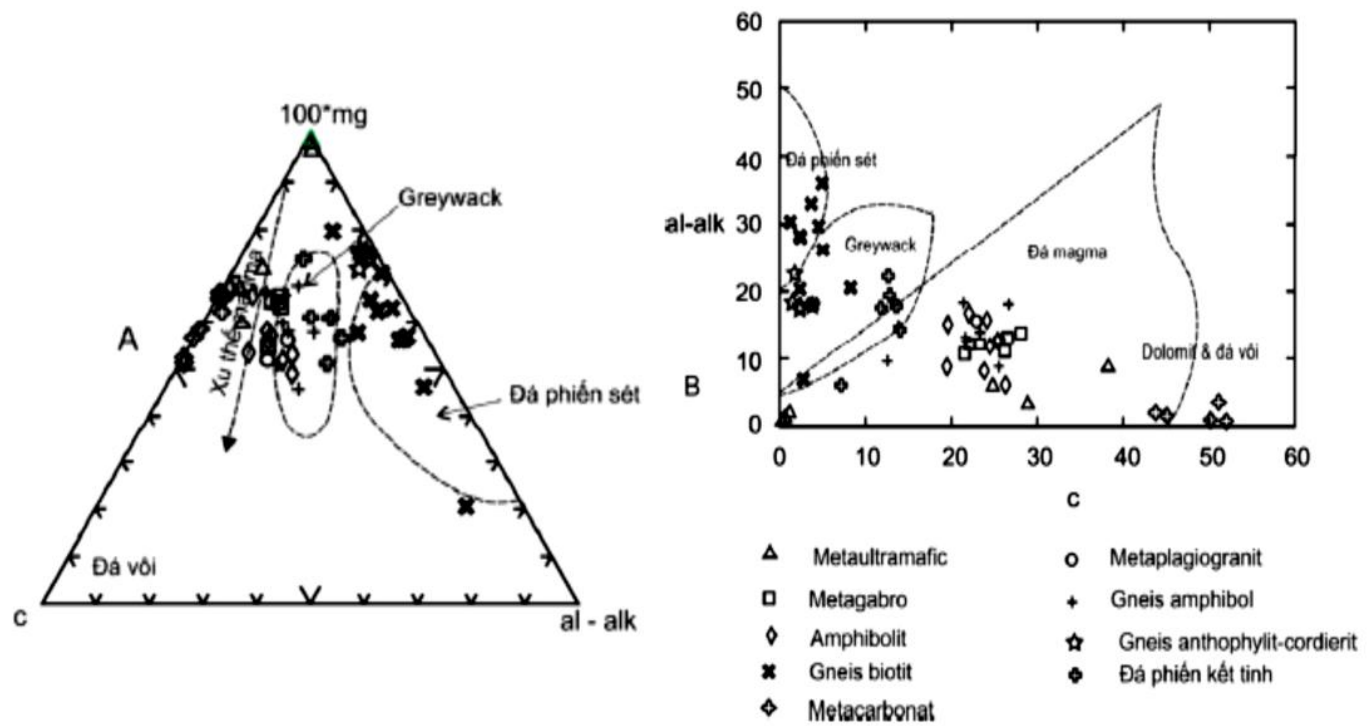

Hình 2. Thành phần nguyên thủy đá biến chất khu vực Kon Rá (Trần Duân, 2021).

+ Đá granit chứa biotit hạt nhỏ vừa bị cà nát và gneis hóa yếu, kích thước hạt thay đổi $0,3 \div 2,4$ $\mathrm{mm}$. Plagioclas acid - trung tính (oligioclas, andesin) $(33 \div 31 \%)$ dạng tấm chũ nhật bị gặm mòn, kích thước thay đổi từ 0,3 x 0,5 mm đến 1,6 x 2,4 mm. Đa số plagioclas bị sericit hóa khá mạnh đều khắp tinh thể. Felspat kali (orthoclas) dạng tấm kém tự hình $(35 \div 36 \%)$, kích thước $0,5 \div 1,6$ mm, bị kaolinit hóa phớt nâu. Thạch anh (30\%) đa số bị cà ép, tái kết tinh, hạt tha hình, biến tinh, kích thước $0,2 \div 2,0 \mathrm{~mm}$, trong suốt, không màu, màu giao thoa xám trắng bậc 1 . Biotit dạng tấm vảy $(1 \div 3 \%)$, từ $0,3 \div 0,9 \mathrm{~mm}$, màu nâu, đa sắc từ nâu sậm đến vàng nâu, hầu hết biotit bị chlorit hoá nhiễm sắc lục. Chứa ít quặng, dạng góc cạnh, màu đen, không thấu quang (LK5/2: 71,1 $\div 71,4 \mathrm{~m}$,...) Khoáng vật phụ có apatit, zircon; ít - 1\% sphen

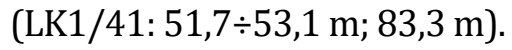

+ Granit biotit: trong khu vực trường quặng chúng bị cà ép, gneis hóa mạnh. Kiến trúc hạt nửa tự hình biến dư. Kích thước hạt thay đổi $0,2 \div 2,4$ mm. Thành phần khoáng vật: Plagioclas acid trung tính (oligioclas, andesin) (khoảng 30\%) dạng tấm chữ nhật bị gặm mòn, kích thước thay đổi từ $0,2 \times 0,3 \mathrm{~mm}$ đến $0,8 \times 1,6 \mathrm{~mm}$. Đa số plagioclas bị sericit hóa khá mạnh và đều khắp tinh thể. Felspat kali (orthoclas) $(35 \div 34 \%)$ dạng tấm kém tự hình, kích thước $0,2 \div 1,6 \mathrm{~mm}$, bị kaolinit hóa phớt nâu. Thạch anh (khoảng 30\%) hạt tha hình, biến tinh, kích thước $0,2 \div 1,4 \mathrm{~mm}$, trong suốt, không màu, màu giao thoa xám trắng bậc 1 . Biotit dạng tấm vảy $(5 \div 8 \%)$, từ $0,2 \div 0,8 \mathrm{~mm}$, hầu hết biotit bị chlorit hoá nhiễm sắc lục, carbonat hóa mạnh. Các khoáng vật phụ gồm: apatit, zircon, khảm trên felspat hay đi cùng biotit, sphen (LK8, độ sâu 296,8 302,0 m). Khoáng vật quặng dạng góc cạnh, màu đen, không thấu quang

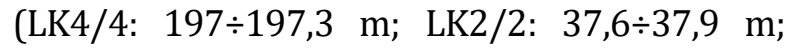
LK2/4: 81,1 $\div 81,4 \mathrm{~m}$ ).

\subsection{2. Đăc điểm đới biển đổi}

Granit xuyên cắt các thành tạo biến chất (đá phiến thạch anh - mica, đá hoa, gneis biotit chứa granat, gneis amphibol, amphibolite, đá phiến chứa graphit xen đá hoa, đá phiến chứa dolomit,... tạo nên đới biến đổi ngoại tiếp xúc có thành phần là diopxit (đặc trưng ở lỗ khoan LK1: 90\%; LK3: $14-15 \%, \ldots)$, pyropxen, tremolit, actinolit $(20 \%$ : KR.LK3/32 (63,5 - 64,5m), chlorit, canxit, wollastonit (KR.LK1/44 $(67,5 \div 67,9) \mathrm{m}: 30 \%$ ), spinel (KR.LK3/7: 14,5 $\div 15,5 \mathrm{~m}$ ), phlogopit (KR.LK3: 13,8 m),... Đặc điểm đới này tương ứng với đới skarnoid, chứa quặng đồng, urani, molipden, sắt. Biến đổi skarn đặc trưng gặp ở LK3: ở độ sâu $15 \mathrm{~m}$ với thành phần gồm tremolit $(10 \div 13 \%)$, plagioclas, sericit $(40 \div 41 \%)$, thạch anh $(5 \div 7 \%)$, felspat kali $(5 \div 7 \%)$, albit $(2 \div 3 \%)$, vesuvian $(1 \%)$, canxit $(2 \div 3 \%)$, chlorit $(5 \div 7 \%)$, zoisit - epidot $(7 \div 9 \%)$, sphen $(7 \div 8 \%)$, fluorit $(1 \div 2 \%)$, quặng $5 \div 6 \%$, muscovite $(1 \div 2 \%)$, ít serpentin, clynopyropxen, apatit; ở độ sâu $78,8 \div 80,4$ m gặp pyropxen $(14 \div 15 \%)$, canxit biến

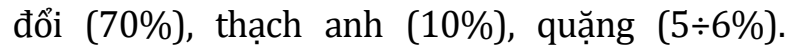
Ngoài ra, còn gặp các khu vực xuất hiện đá hoa, các 
đới biến đổi chlorit hóa trên nền đá phiến.

+ Granit bị biến đổi: anbit hóa gặp trong đá granit chứa biotit hạt không đều bị cà nát yếu, kích thước hạt thay đổi $0,3 \div 3,0 \mathrm{~mm}$. Felspat kali (orthoclas) bị albit hóa dạng đốm vết. Sericit hóa: plagioclas dạng tấm bị gặm mòn cà nát, đa số bị sericit hóa đều khắp tinh thể. Chlorit hóa xuất hiện trên biotit dạng tấm vảy, chlorit hóa mạnh gặp ở các độ sâu khác nhau.

Phần nông (LK1/13: 19,2 $\div 20,2$ m), anbit hóa xảy ra mạnh mẽ hơn so với sericit hóa và ngược lại, quá trình sericit xảy ra mạnh mẽ hơn ở phần sâu (LK1/32: 42,0 $\div 43,1$ m). Thậm chí, ở dưới sâu chỉ có quá trình sericit hóa mà không thấy hiện tượng anbit hóa. Như vậy, quá trình này có thể ảnh hưởng đến những giai đoạn sinh khoáng khác nhau. Trong đó, khối magma ở đây khi đi lên còn có xu hướng xuyên ngang vào các đới xung yếu/lớp xung yếu (hình thành dạng răng lược hay thể sill). Vì thế, theo độ sâu các lỗ khoan gặp hiện tượng xen kẹp giữa đá vây quanh và các thể granit. Một số tác giả gọi các thể này là granit không chân.

+ Ngoài ra, đối với granit hạt nhỏ (kích thước hạt thay đổi $0,2 \div 1,6 \mathrm{~mm}$ ), sáng màu ở phần sâu cũng bị anbit hóa yếu hơn hiện tượng sericit hóa (LK5/161: 296,8 $\div 302,0 \mathrm{~m}$ ).

\subsection{3. Đặc điểm và điều kiện thành khoáng vật quặng theo các giai đoạn}

Chalcopyrit $\left(\mathrm{CuFeS}_{2}\right)$ có dạng hạt nhỏ tha hình, kích thước hạt từ $0,01 \div 0,5 \mathrm{~mm}$, thường phân bố xen kẽ trong đám melhicovit. Ngoài ra, còn có dạng các hạt nhỏ, vi mạch ngắn do xen lấp vào ranh giới khe nứt, khe cát khai của các hạt phi quặng.

Molybdenit $\left(\mathrm{MoS}_{2}\right)$ bắt gặp ở dạng tấm nhỏ xen vào trong nền menicovit. Kích thước tấm khoảng $(0,1 \div 0,15) \times(0,4 \div 0,7) \mathrm{mm}$. Molybdenit xuất hiện khá nhiều ở độ sâu từ $6 \div 20 \mathrm{~m}$, mẫu khoáng tướng kiểm tra $2 \div 3 \%$ gần trên mặt địa hình, $5 \div 15 \%$ dạng nửa tự hình - tha hình (độ sâu $13,5 \div 14,5 \mathrm{~m}$ ) đi kèm ít uraninit. Kích thước khoáng vật $0,1 \div 1,5 \mathrm{~mm}$ theo chiều ngang. Molybdenit thành tạo trước pyrit. Uraninit, còn xuất hiện trong đới nội tiếp xúc của đá granit pegmatit, molipdenit trong granit hạt nhỏ - vừa nhưng sâu trong nội khối hơn so với đới giàu xạ (uraninit,... kết quả đo phổ $U=0,17 \div 0,2 \%$, xạ $3.420 .000 \div 8.020 .000 \mu \mathrm{R} / \mathrm{h}$ tại vết lộ KR109).

- Melnicovit $\left(\mathrm{Fe}_{2}+\mathrm{Fe}_{3}+\mathrm{S}_{4}\right)$ phổ biến nhất, chúng có dạng keo, đới keo, tạo thành các đám ổ lớn, bao quanh, gắn kết các hạt phi quặng.

- Trong chalcopyrit có một số hạt pyrotin ( $\mathrm{Fe}_{1}$ $\left.{ }_{-x} S_{n}\right)$ kích thước nhỏ $(0,01 \mathrm{~mm})$. Tuy nhiên, một số mẫu pyrotin đạt đến $60 \div 65 \%$ (KR.01), sinh sớm hơn chalcopyrit, hạt nhỏ tha hình, phân bố thành các ổ nhỏ xen lấp trong các khe nứt phi quặng.

Quặng được thành tạo trong khoảng nhiệt độ $205 \div 297$ 0C $(109 / 2 ; 124 ; 127 ; 129 ; 140 / 1$; 150/7). Một số đới quặng xâm nhiễm trong đới nội tiếp xúc hoặc ngoại tiếp xúc có pha khí - lỏng, nhiệt độ cao $\left(357 \div 425^{\circ} \mathrm{C}\right)$ nhưng chỉ đới nội tiếp xúc có mật độ cao, còn đới ngoại tiếp xúc mật độ thấp (Nguyễn Tiến Dũng và nnk., 2020) nên nhiệt độ này không đặc trưng cho giai đoạn tạo quặng ở Kon Rá.

\section{3. Đặc điểm địa hóa các thành tạo địa chất khu vực trườngquặng Kon Rá}

\subsection{1. Đặc điểm địa hóa đá magma acid và quặng hóa liên quan}

Trên cơ sở nhóm nguyên tố chính, phân chia các đá granit trong trường quặng Kon Rá đều thuộc kiểu I granit gồm : granit hạt nhỏ, granit hạt vừa sáng màu (KR10, LK2/1, LK8/1, LK9/1). Granit hạt vừa nhưng bị cà nát - biến đổi mạnh nằm ở ranh giới giữa trường I và $S$ nhưng nghiêng về I granit nhiều hơn (KR118, gần điểm quặng Cu chứa molipdenit và cùng hệ thống đứt gãy, biotit có màu nâu). Granit pegmatit hạt vừa ở ranh giới nội tiếp xúc thuộc trường $S$ - granit do bị biến đổi (KR109 : chlorit hóa, epidot hóa, anbit hóa ; xạ rất cao, chứa molipdenit. Riêng granit hạt lớn (bị mạch thạch anh sulfua chứa đồng xuyên cắt : KR150), mẫu lấy ở vị trí bị biến đổi ít nên có thể thuộc kiểu S - granit khác với granit hạt nhỏ nêu trên (Hình 3).

Ngoài ra, granit khu vực nghiên cứu có tính oxy hóa, đặc biệt granit hạt nhỏ - sáng màu (Nguyễn Tiến Dũng và nnk., 2020), chúng thường liên quan với kiểu I - granit. Tính chất này còn thể hiện bởi dị thường âm của Eu cùng dị thường dương Tm (Hình 4).

Đặc điểm địa hóa nhóm nguyên tố vết gồm: nhóm nguyên tố đất hiếm nhẹ (LREE) có xu hướng tăng cao, tạo nên đồ hình nghiêng từ trái sang phải và dị thường âm của Eu. Tuy nhiên, dị thường âm Eu của granit hạt nhỏ sáng màu thấp hơn rất nhiều. Ngoài ra, đá ryolit và granit hạt nhỏ dạng 


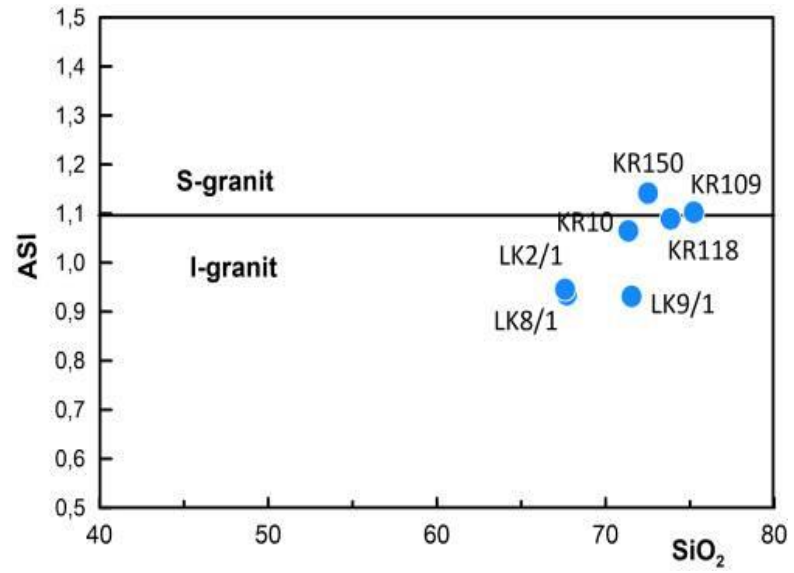

Hình 3. Biểu đồ kiểu granit khu vực Kon Rá.

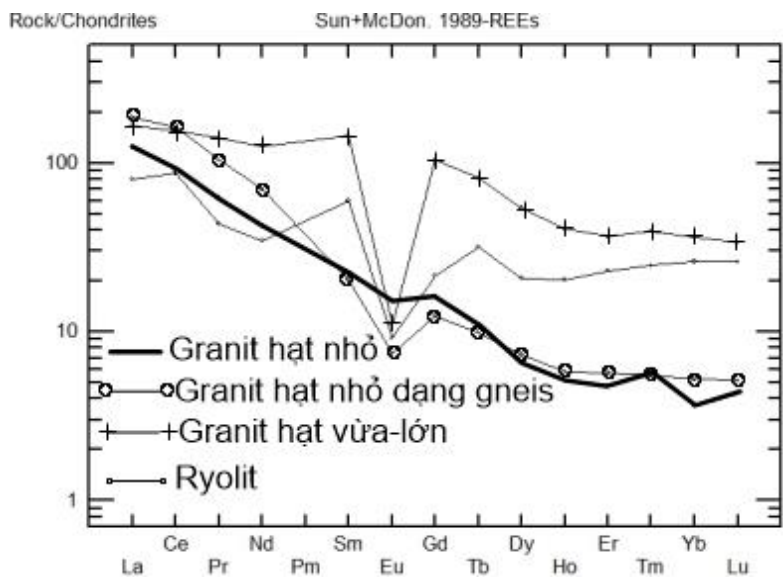

Hình 4. Đặc điểm phân bố nhóm đất hiếm trong các đá magma acid ở trường quặng Kon Rá. gneis còn có dị thường dương Ce. Tổng đất hiếm của granit hạt vừa - lớn cao hơn hẳn các kiểu granit khác và ryolit (tương ứng, $(\mathrm{REE})_{\mathrm{cn}}=777,18$ so với $273,33 \div 399,87)$, đặc biệt nhóm đất hiếm nặng (HREE) (Hình 4).

Đối với granit chứa biotit, granit biotit hạt vừa - nhỏ ít biến đổi có tính chuyên hóa khoáng vật phụ của $\mathrm{Cu}(\mathrm{Ktt}=19)$, chuyên hóa địa hóa của Mo $(\mathrm{Ktt}=4)$, và As $(\mathrm{Ktt}=6)$. Trong khi đó, granit hạt nhỏ sáng màu hơn, hàm lượng các nguyên tố này suy giảm đáng kể, chỉ có chuyên hóa địa hóa ở mức trung bình $-\mathrm{Cu}(\mathrm{Ktt}=3)$, As $(\mathrm{Ktt}=6), \mathrm{Mo}-\mathrm{Pb}(\mathrm{Ktt}$ = 2) (Nguyễn Tiến Dũng và nnk., 2020).

Bên cạnh đó, granit bị dập vỡ sát đới quặng đồng (trong đá biến đổi - dăm kết) có hàm lượng Tb tăng cao (164,26 ppm), gấp 65,7 lần granit và 38 lần vỏ trái đất (Mẫu 104).

3.3.2. Đặc điểm địa hóa thứ sinh (đất) trưòng quặng Kon Rá

Tỷ số hàm lượng $\mathrm{Cu}, \mathrm{Pb}, \mathrm{Zn}$ thể hiện theo đới cắt ngang thân quặng và đới tiếp xúc (nội tiếp xúc, ngoại tiếp xúc) như sau: $\mathrm{Cu}$ tăng cao so với $\mathrm{Pb}, \mathrm{Zn}$ ở đới ngoại tiếp xúc chứa quặng và nội tiếp xúc (điểm 103, 105, 108, 114, 116, 125, 127/1, 139, $141,142,143,149$ theo từng tuyến và mũi tên hướng về trung tâm đới quặng/đới tiếp xúc); ngược lại, càng ra xa đới ngoại tiếp xúc, $\mathrm{Pb}, \mathrm{Zn}$ tăng so với Cu (144; 145 - Đập Kon Rá; đối diện trường quặng Kon Rá qua sông Đăk Akoi; 148, 149) (Hình 5). Tuy nhiên, phân bố trên không luôn tuyến tính

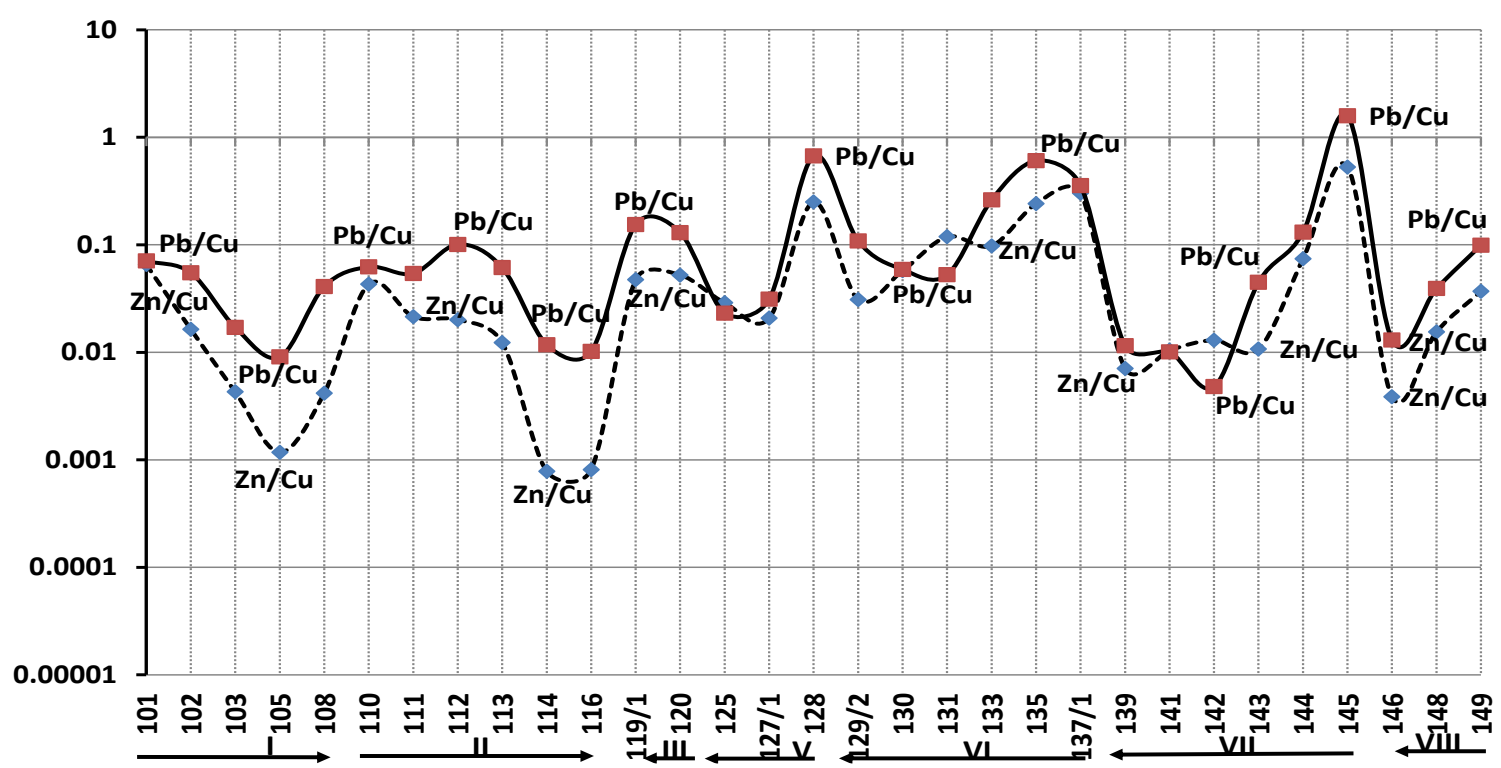

Hình 5. Đặc điểm phân đới kim loại $\mathrm{Pb}, \mathrm{Zn}, \mathrm{Cu}$ trong đất trường quặng Kon Rá (I - số hiệu tuyến và hướng đới quặng/đới tiếp xúc). 
vì hành vi của $\mathrm{Pb}, \mathrm{Zn}, \mathrm{Cu}$,... còn phụ thuộc vào nhiều yếu tố địa chất khác.

Hàm lượng $\mathrm{Fe}_{2} \mathrm{O}_{3}$ cũng tăng cao ở đới biến đổi ngoại tiếp xúc chứa quặng đồng và xạ cao (103, 105, 108); $\mathrm{MgO}, \mathrm{CaO}, \mathrm{P}_{2} \mathrm{O}_{5}$ cũng tương tự (Hình 6). Tuy nhiên, sự phân bố hàm lượng của CaO cũng có những khác biệt nhất định so với ba thành phần trên: $\mathrm{CaO}$ giảm hàm lượng mạnh tại các điểm 142 (khu vực nội tiếp xúc của granit), 143, 145 (đất phát triển trên đá phiến, đá phiến bị micmatit hóa), tăng ở điểm 139, 146 (đất trên đá phiến, khu vực ngoại tiếp xúc) (Hình 6).

$\mathrm{K}_{2} \mathrm{O}$ thường tăng cao hàm lượng trong đất phủ trên đới nội tiếp xúc (granit): điểm 108, 125, 127/1, 135, 141, 142; đất trên thân quặng sát đới nội tiếp xúc (119/1). Đồng thời, cũng tăng cao ở vị trí thuộc khu vực giàu sét - bột, bột - cát màu vàng (xuất hiện những mảnh vụn thạch anh, tảng lăn quartzit) cách xa thân quặng $(111,112,113,120)$ (Hình 7).

MnO biến đổi phức tạp, nhưng rõ ràng nhất là đất màu vàng, xám vàng giàu bột sét, bột thì hàm lượng suy giảm rất mạnh. Đất này phát triển trên các đá biến chất hệ tầng Tắc Pỏ $(101,110,111$, $128,133,135,149)$ hoặc đá granit $(137 / 1)$. Nếu xét theo quan hệ đới nội tiếp xúc và đới ngoại tiếp xúc chứa quặng hóa đồng thì $\mathrm{MnO}$ tăng ở phía xa phần đới ngoại tiếp xúc (130). $\mathrm{TiO}_{2}$ gần như phân bố ngược lại (Hình 7), có thể liên quan đến các thành phần khoáng vật như sphen.

As có sự biến đổi tăng dần hàm lượng từ đới gần quặng sulfua đồng giàu xạ (U; $106.000 \mu \mathrm{R} / \mathrm{h})$ $(129 / 2)$ ra phía ngoài (131) (Hình 8). Đồng thời tiến vào phía nội khối granit $(133,135,137 / 1)$ hàm lượng As cũng suy giảm mạnh (dưới giới hạn phân tích).

Tổ hợp đặc trưng các nguyên tố trong đất trường quặng Kon Ra gồm: $\mathrm{Cu}-\mathrm{Fe}^{3+}-\mathrm{Mn}^{2+}-\mathrm{Zn}$ $\mathrm{Ca}^{2+}$ - $\mathrm{Co}-\mathrm{P}^{5+}, \mathrm{Al}$ - $\mathrm{Ga}$ - $\mathrm{La}$ - Ce, $\mathrm{Ba}-\mathrm{Sr}-\mathrm{K}, \mathrm{V}$ - Zn $\mathrm{Pb}, \mathrm{Ni}$ - Cr (Bảng 1).

\subsection{3. Đặc điểm địa hóa đói quặng}

Theo Nguyễn Tiến Dũng và nnk. (2020), đới quặng đồng (urani, molipden), Cu đi với U - Ni (Co) nhưng không đi cùng Mo; đới quặng đồng giàu rất giàu Mo chứa khoáng hóa urani (uraninit) có tổ hợp cộng sinh nguyên tố: $\mathrm{Cu}-\mathrm{Co}$ - Ni, U - Mo $\mathrm{Ni}, \mathrm{U}$ - Co - Ni, các tổ hợp nguyên tố này có quan hệ nghịch với As; đới quặng đồng giàu Mo, U (uraninit), $\mathrm{Cu}$ đi với Co - Ni và tương quan nghịch

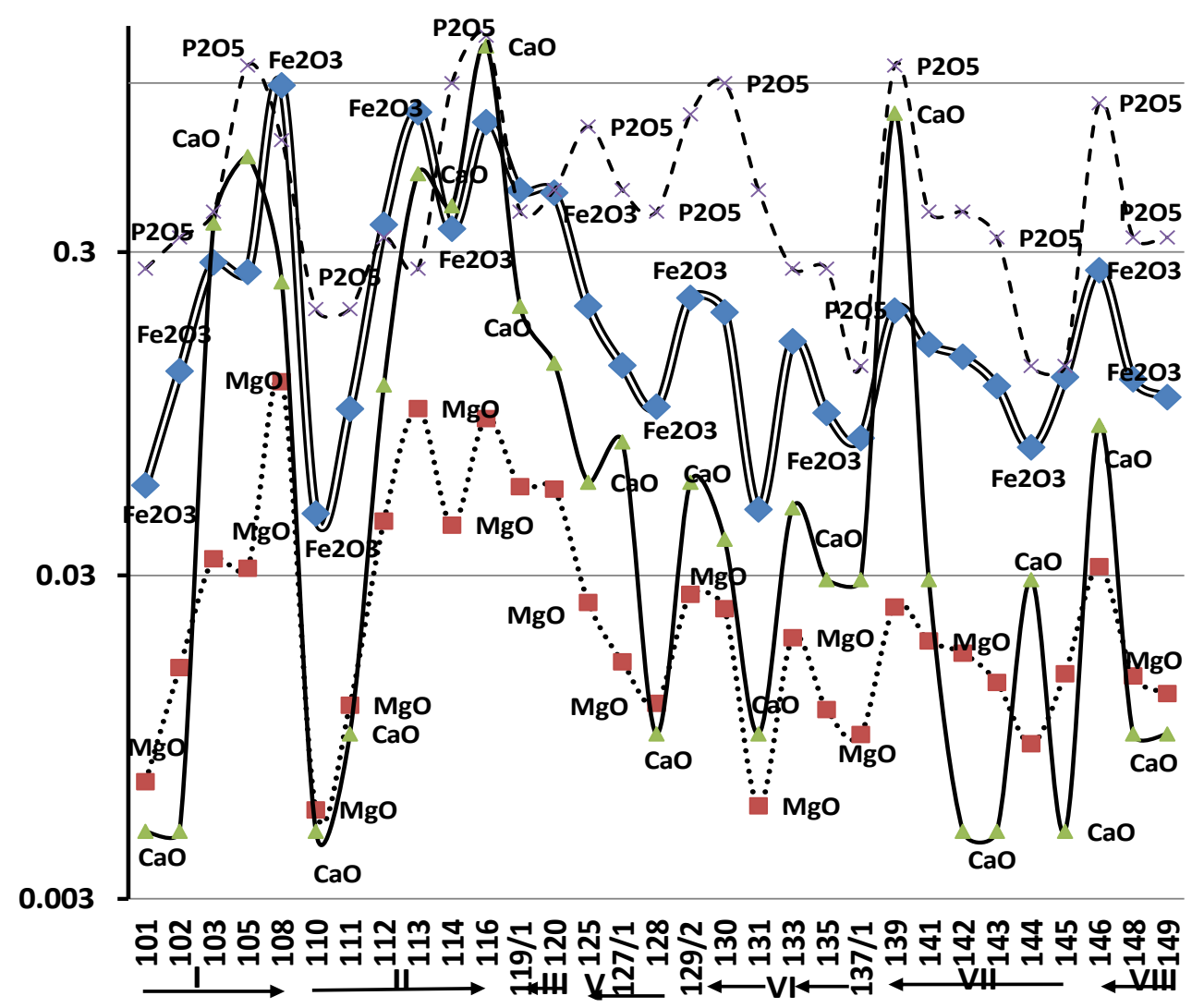

Hình 6. Đặc điểm phân đới kim loại $\mathrm{Fe}, \mathrm{Ca}, \mathrm{Mg}$, P trong đất trường quặng Kon Rá. 


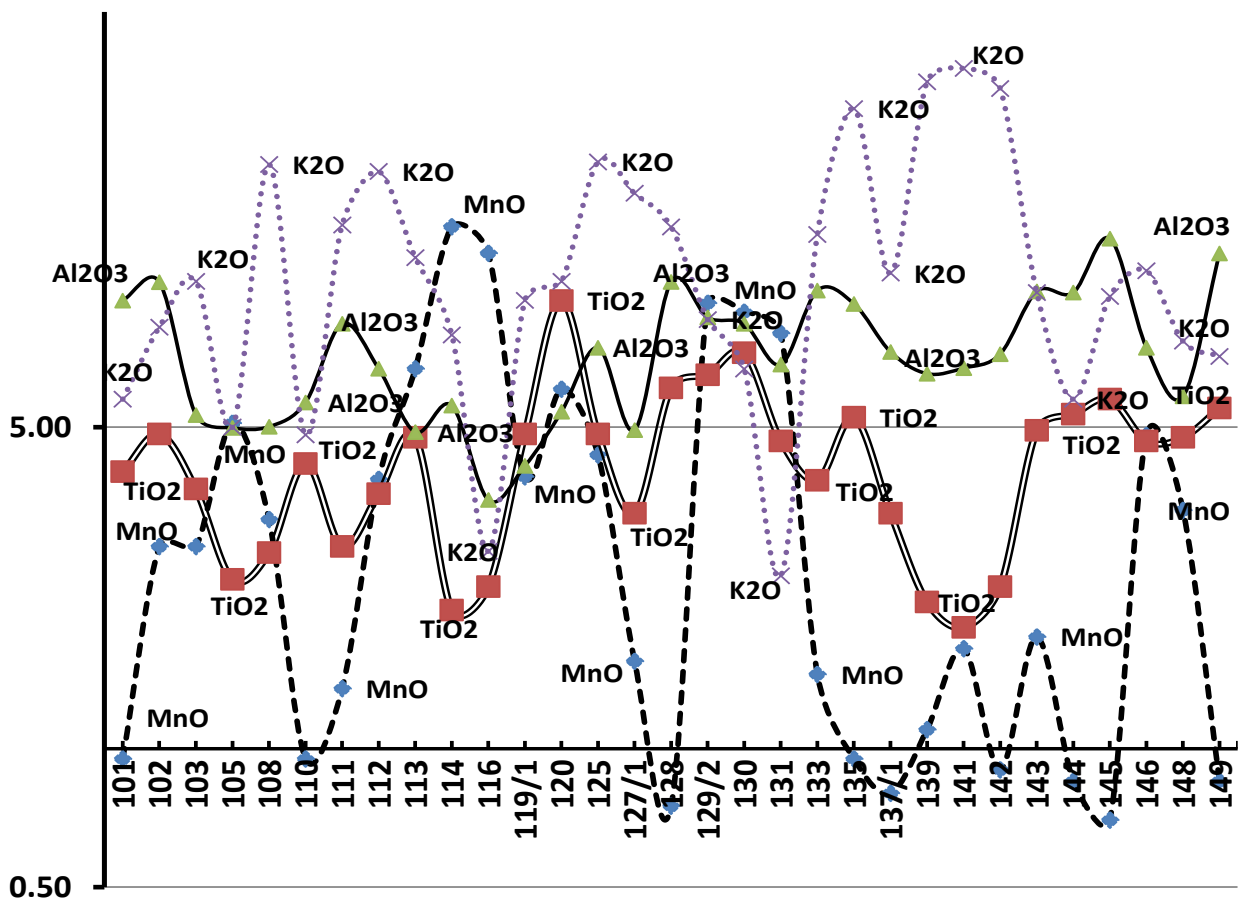

Hình 7. Đặc điểm phân đới kim loại Mn, Al, Ti, K trong đất trường quặng Kon Rá (phân đới ngang).

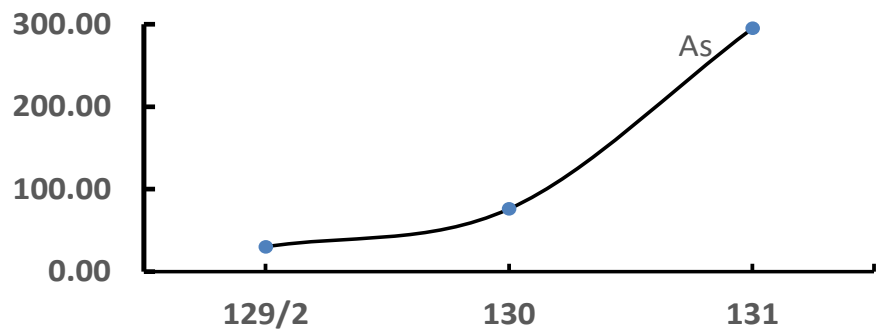

Hình 8. Đặc điểm phân đói kim loại As trong đất trường quặng Kon Rá.

Bảng 1. Hệ số tương quan các nguyên tố trong đất của trường quặng đồng Kon Ra (32 mẫu).

\begin{tabular}{|c|c|c|c|c|c|c|c|c|c|c|c|c|c|c|c|c|c|c|c|c|c|c|c|c|c|c|}
\hline & $\mathrm{Al}_{2}$ & $\mathrm{~B}$ & $\mathrm{Ba}$ & $\mathrm{Be}$ & $\mathrm{Ca}$ & $\mathrm{Ce}$ & $\mathrm{Co}$ & $\mathrm{Cr}$ & $\mathrm{Cu}$ & $\mathrm{Fe}_{2}$ & $\mathrm{Ga}$ & $\mathrm{K}_{2}$ & $\mathrm{La}$ & $\mathrm{Li}$ & $\mathrm{Mg}$ & $\mathrm{Mn}$ & $\mathrm{Nb}$ & $\mathrm{Ni}$ & $\mathrm{P}_{2} \mathrm{O}$ & $\mathrm{Pb}$ & $\mathrm{Sc}$ & $\mathrm{Sr}$ & $\mathrm{TiO}$ & $\mathrm{V}$ & $\mathrm{Y}$ & $\mathrm{Zn}$ \\
\hline $\mathrm{Al}_{2}$ & 1 & & & & & & & & & & & & & & & & & & & & & & & & & \\
\hline $\mathrm{B}$ & - & 1 & & & & & & & & & & & & & & & & & & & & & & & & \\
\hline $\mathrm{Ba}$ & - & 0,1 & 1 & & & & & & & & & & & & & & & & & & & & & & & \\
\hline $\mathrm{Be}$ & 0,3 & 0,6 & 0,1 & 1 & & & & & & & & & & & & & & & & & & & & & & \\
\hline $\mathrm{Ca}$ & - & - & 0,0 & 0,6 & 1,0 & & & & & & & & & & & & & & & & & & & & & \\
\hline $\mathrm{Ce}$ & 0,5 & 0,1 & 0,0 & 0,3 & - & 1 & & & & & & & & & & & & & & & & & & & & \\
\hline $\mathrm{Co}$ & - & - & - & 0,3 & 0,6 & - & 1 & & & & & & & & & & & & & & & & & & & \\
\hline $\mathrm{Cr}$ & 0,0 & 0,0 & - & - & - & - & 0,0 & 1 & & & & & & & & & & & & & & & & & & \\
\hline $\mathrm{Cu}$ & - & - & - & 0,4 & 0,7 & - & 0,9 & - & 1 & & & & & & & & & & & & & & & & & \\
\hline $\mathrm{Fe}$ & - & - & - & 0,3 & 0,6 & - & 0,9 & 0,0 & 0,9 & 1 & & & & & & & & & & & & & & & & \\
\hline $\mathrm{Ga}$ & 0,8 & - & - & 0,5 & - & 0,4 & - & - & - & - & 1 & & & & & & & & & & & & & & & \\
\hline $\mathrm{K}_{2} \mathrm{O}$ & - & 0,3 & 0,6 & - & - & 0,1 & - & - & - & - & - & 1 & & & & & & & & & & & & & & \\
\hline $\mathrm{La}$ & 0,5 & 0,2 & 0,1 & 0,4 & - & 0,9 & - & - & - & - & 0,5 & 0,3 & 1 & & & & & & & & & & & & & \\
\hline $\mathrm{Li}$ & 0,2 & - & 0,0 & - & - & - & - & 0,3 & - & - & 0,2 & - & - & 1 & & & & & & & & & & & & \\
\hline $\mathrm{Mg}$ & - & - & 0,2 & - & 0,5 & - & 0,4 & - & 0,4 & 0,3 & - & 0,0 & - & 0,1 & 1 & & & & & & & & & & & \\
\hline
\end{tabular}




\begin{tabular}{|c|c|c|c|c|c|c|c|c|c|c|c|c|c|c|c|c|c|c|c|c|c|c|c|c|c|c|}
\hline $\mathrm{Mn}$ & - & - & - & 0,3 & 0,4 & - & 0,8 & 0,2 & 0,7 & 0,7 & - & - & - & 0,0 & 0,4 & 1 & & & & & & & & & & \\
\hline $\mathrm{Nb}$ & - & - & 0,0 & - & - & 0,1 & - & 0,2 & - & - & - & 0,1 & 0,0 & 0,4 & 0,2 & 0,1 & 1 & & & & & & & & & \\
\hline $\mathrm{Ni}$ & - & - & - & 0,0 & 0,1 & - & 0,0 & 0,4 & - & 0,0 & - & - & - & 0,1 & - & - & 0,1 & 1 & & & & & & & & \\
\hline $\mathrm{P}_{2} \mathrm{O}$ & - & - & - & 0,8 & 0,6 & - & 0,7 & - & 0,7 & 0,6 & - & - & - & - & 0,3 & 0,6 & 0,0 & - & 1 & & & & & & & \\
\hline $\mathrm{Pb}$ & 0,0 & - & - & 0,3 & - & 0,1 & 0,0 & 0,2 & 0,0 & 0,3 & - & - & - & - & - & 0,3 & 0,1 & - & 0,0 & 1 & & & & & & \\
\hline Sc & 0,3 & - & - & 0,0 & - & - & 0,1 & 0,5 & \begin{tabular}{|l|} 
\\
\end{tabular} & 0,2 & - & - & - & 0,3 & \begin{tabular}{|l|} 
\\
\end{tabular} & 0,3 & 0,1 & 0,2 & 0,0 & 0,4 & 1 & & & & & \\
\hline $\mathrm{Sr}$ & 0,1 & - & 0,8 & 0,5 & 0,0 & 0,1 & - & - & - & - & 0,1 & 0,4 & 0,2 & 0,0 & 0,1 & - & - & - & - & - & - & 1 & & & & \\
\hline $\mathrm{TiO}$ & 0,3 & - & - & - & - & 0,0 & - & 0,4 & - & - & 0,2 & - & 0,0 & 0,7 & - & 0,0 & 0,4 & 0,1 & - & 0,1 & 0,5 & $\underline{0,1}$ & 1 & & & \\
\hline \begin{tabular}{|l|}
$\mathrm{V}$ \\
\end{tabular} & 0,0 & - & - & 0,0 & - & - & 0,3 & 0,5 & 0,1 & 0,4 & - & - & - & 0,2 & 0,0 & 0,5 & 0,2 & 0,1 & 0,2 & 0,7 & 0,8 & - & 0,5 & 1 & & \\
\hline $\mathrm{Y}$ & - & 0,4 & 0,1 & 0,7 & - & 0,2 & 0,0 & 0,1 & 0,0 & - & - & 0,2 & 0,3 & 0,0 & - & 0,0 & 0,2 & 0,2 & 0,1 & - & 0,0 & - & - & - & 1 & \\
\hline $\mathrm{Zn}$ & - & - & - & 0,2 & 0,3 & - & 0,8 & 0,2 & 0,7 & 0,8 & - & - & - & 0,0 & 0,3 & 0,8 & - & - & & 0,4 & 0,6 & - & & 0,7 & - & 1 \\
\hline
\end{tabular}

với As. Nếu xét riêng cho đới quặng đồng có Mo đi kèm, $\mathrm{Cu}$ cộng sinh cùng $\mathrm{Co}$ - Ni và hành vi ngược với As. Theo phạm vi toàn bộ đới quặng đồng (cả ba đới nêu trên), $\mathrm{Cu}$ luôn đi cùng $\mathrm{Co}-\mathrm{Ni}, \mathrm{U}$ đi cùng với $\mathrm{Ni}, \mathrm{Pb}$; mặt khác $\mathrm{Cu}$ có xu hướng tách biệt với $\mathrm{Au}, \mathrm{U}$, As nhưng không rõ ràng, $\mathrm{U}$ tách biệt với Co; $\mathrm{Pb}$ và $\mathrm{Zn}$ không có quan hệ với nhau.

Tỷ số đất hiếm nhẹ (La) so với Y tăng cao trong đất ở đới xa quặng, ngược lại, Y tăng cao ở khu vực đất phát triển trên đới quặng đồng và đới sulfua có xạ cao $(105,108,114,116,119 / 1$, 129/2, 133, 139) (Hình 9).

Đặc điểm nhóm nguyên tố REE của hai loại (kiểu) quặng đồng (Loại I - thân quặng trong đới biến đổi, II - dạng mạch: các Hình 10 và 11 ) tương tự nhau về đồ hình. Tỷ số LREE và HREE của hai kiểu (loại) quặng này khá giống nhau: $(\mathrm{La} / \mathrm{Lu})_{\mathrm{cn}}=$ 4,00 (Loại I) và 5,17 (Loại II); $(\mathrm{Ce} / \mathrm{Yb})_{\mathrm{cn}}=7,10$ (Loại I) và 5,60 (Loại II). Tuy nhiên, quặng đồng trong đới biến đổi ngoại tiếp xúc (Loại I) thể hiện tổng REE thấp hơn so với quặng dạng mạch thạch anh sulfua đồng xuyên cắt granit hạt vừa - lớn (Loại II), đồng thời dạng đồ hình của HREE phân bố phức tạp. Mặt khác, hai loại quặng này đều có dị thường dương của Ce và âm của Eu, riêng quặng loại I còn có dị thường dương của Tb (Hình 10).

Địa hóa khoáng vật quặng đặc trưng bởi sự làm giàu $C$ trong pyrit hạt nhỏ $(0,1 \div 1 \mathrm{~mm})$, tha hình phân bố trong các khe nứt đá biến đổi, đồng thời pyrit này còn chứa $\mathrm{Au}$ (Hình 12 , Bảng 2 ).

\section{Bảng 2. Thành phần khoáng vật pyrit trong mạch quặng đồng ở Kon Rá (Phân tích bằng phương pháp EDS).}

\begin{tabular}{|c|c|c|c|}
\hline Nguyêntố & $\begin{array}{c}\text { \%trọng } \\
\text { lượng }\end{array}$ & $\begin{array}{c}\text { Tổng \%trọng } \\
\text { lượng }\end{array}$ & $\begin{array}{c}\text { \% nguyên } \\
\text { tử }\end{array}$ \\
\hline $\mathrm{S}$ & 37,12 & 0,44 & 36,88 \\
\hline $\mathrm{Fe}$ & 46,02 & 0,54 & 26,25 \\
\hline
\end{tabular}

\begin{tabular}{|c|c|c|c|}
\hline $\mathrm{C}$ & 11,21 & 0,94 & 29,72 \\
\hline $\mathrm{O}$ & 3,16 & 0,24 & 6,30 \\
\hline $\mathrm{Al}$ & 0,21 & 0,04 & 0,24 \\
\hline $\mathrm{Si}$ & 0,25 & 0,03 & 0,29 \\
\hline $\mathrm{Au}$ & 2,03 & 0,24 & 0,33 \\
\hline Total & 100,00 & & 100,00 \\
\hline
\end{tabular}

\subsection{Thảo luận}

Quá trình tiếp xúc của granit tuổi trias trùng với giai đoạn biến chất $(\mathrm{T})$ của khu vực với các đá vây quanh nguyên thủy trước trias là đá phiến, đá vôi - dolomit, greywack. Do thành phần đá vây quanh không đồng nhất nên nó có thể tạo ra các đới biến đổi khác nhau. Cụ thể:

+ Skarnoid cùng những dạng như sừng hóa đi kèm nên được lý giải theo kiểu skarnoid - hornfles (biến chất trao đổi kiểu trung gian bimetasomatism): Giai đoạn phụ này là hệ quả của quá trình thay thế trao đổi giữa magma với đá vây quanh chứa các lớp xen kẽ của cacbonat giàu sét, đá phiến sét. Quá trình biến chất làm cho đá vôi bị kết tinh lại, phát triển cấu tạo khảm đều. Tuy nhiên, trong các lớp sét xen kẹp, ngoài các canxit kết tinh lại, một loạt các silicat vôi hạt mịn, nghèo Fe (clinopyroxen) đã được phát triển (skarnoid hornfels; đá hoa chứa pyroxen). Không có hoặc một lượng không đáng kể các khoáng vật không trong suốt (oxit và/hoặc sulfua) được hình thành trong giai đoạn này.

Biến chất trao đổi trung gian (bimetasomatic) đi kèm với phản ứng khử cacbon thường hình thành nên các khe nứt trong đá vây quanh chứa vôi. Loại khe nứt này, là kết quả của áp suất tăng do magma đi lên và phát triển cùng pha chất lỏng (tạo khe nứt do nhiệt dịch: hyro - fracturing), phát triển các khu vực có dung thể xâm nhập vào đá 


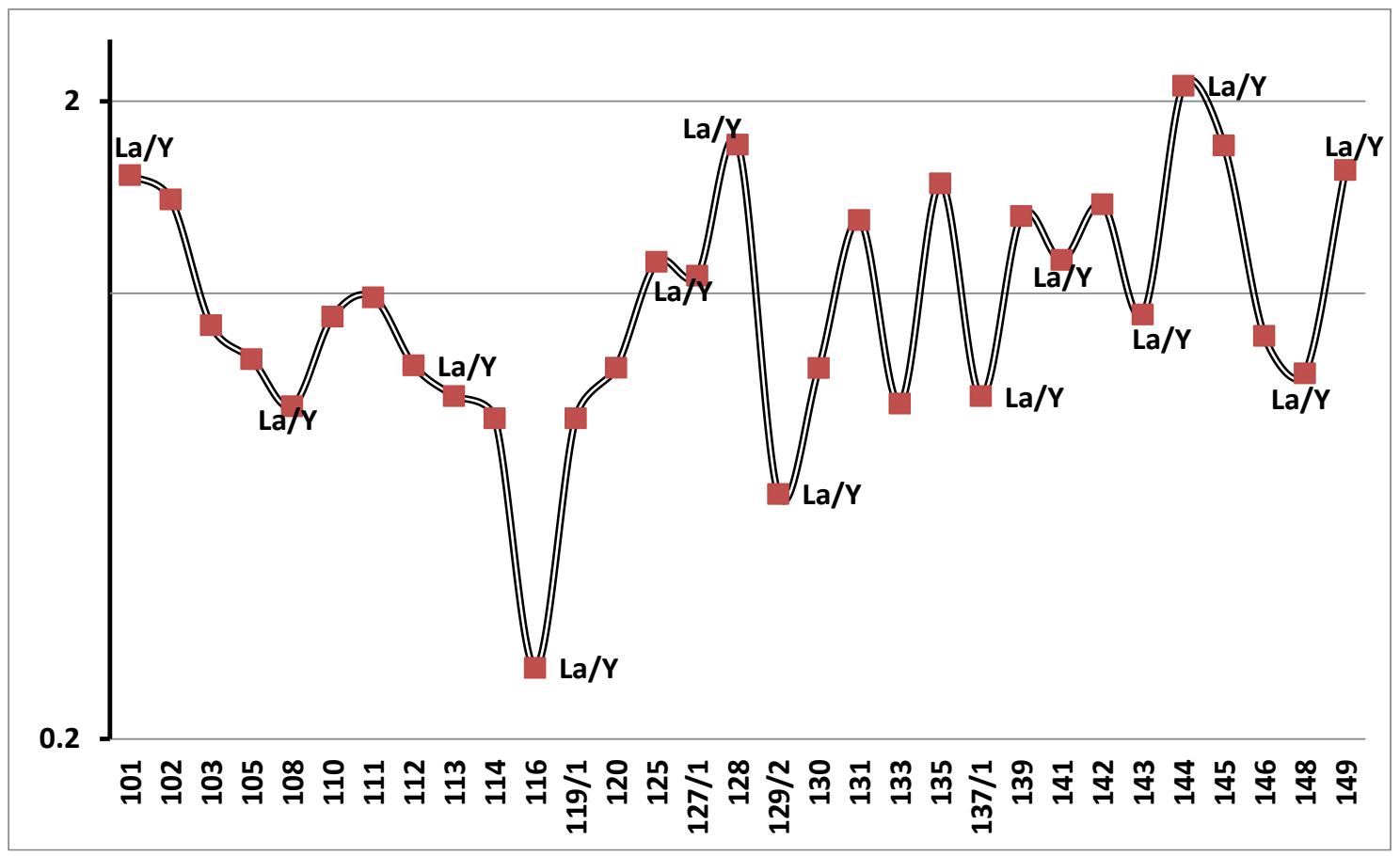

Hình 9. Đặc điểm tỷ số đất hiếm nhẹ (La) và nhóm nặng (Y) trong đất trường quặng Kon Rá.

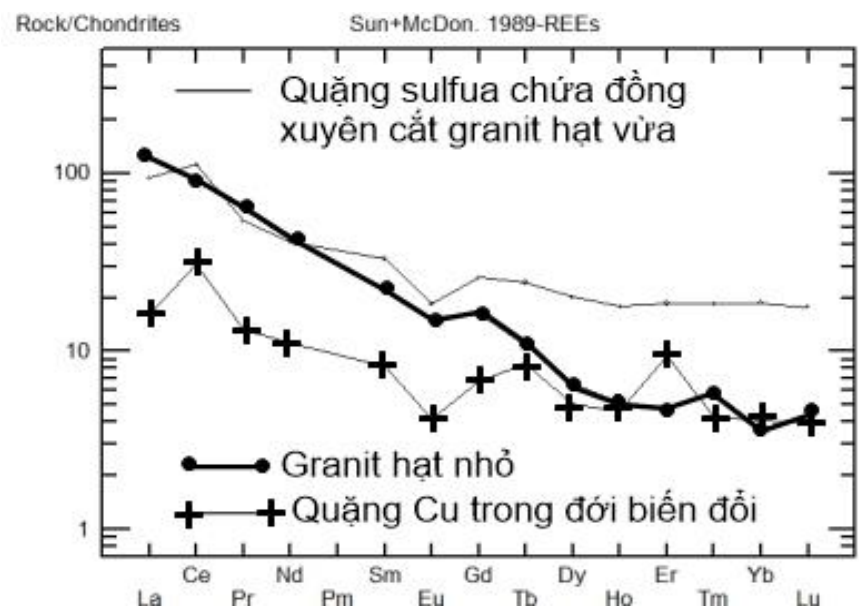

Hình 10. Đặc điểm phân bố nhóm đất hiếm trong hai kiểu quặng ở Kon Rá và granit hạt nhỏ.

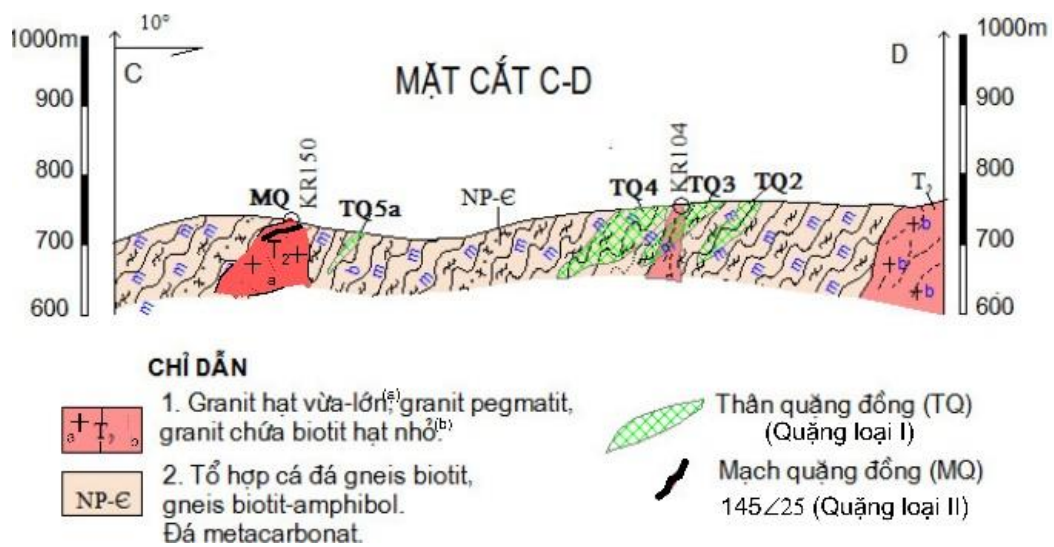

Hình 11. Mặt cắt địa chất về đặc điểm phân bố hai loại quặng (loại I, II) khu vực Kon Rá. 


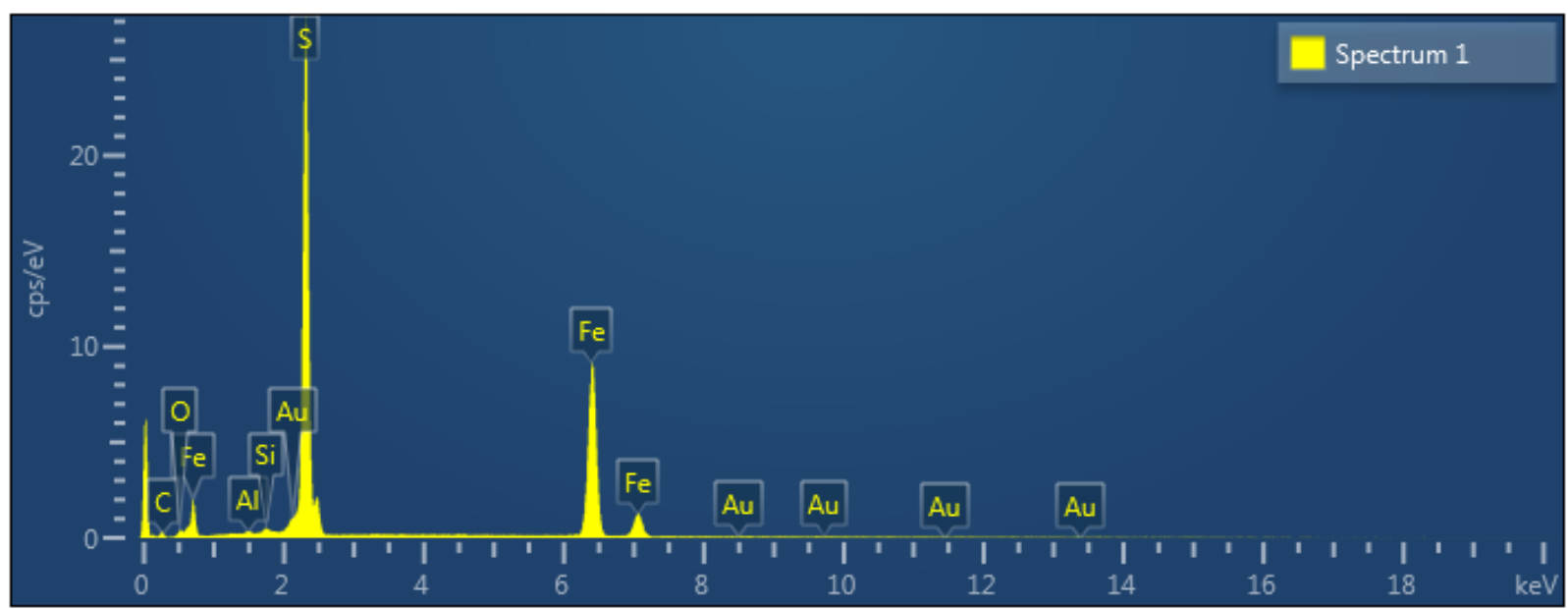

Hình 12. Biểu đồ phổ thành phần nguyên tố trong khoáng vật pyrit của quặng đồng Kon Rá.

biến chất (đá hoa) - đá biến chất trao đổi trung gian (skarnoid - hornfels). Bằng chứng của quá trình biến chất trao đổi này (bimetasomatic alteration) là sự xuất hiện một loạt các khoáng vật silicat - vôi không chứa nước, giàu sắt, hạt trung bình đến thô (Diopxit, pyropxen).

+ Giai đoạn biến chất trao đổi giật lùi (retrograde metasomatic stage): nghiên cứu thạch học chỉ ra rằng giai đoạn biến chất trao đổi giật lùi, thành tạo sau giai đoạn tiến hóa (prograde metasomatic stage), tạo nên các khoáng vật ngậm nước (actinolit, tremolit, chlorit, trong khu vực xuất hiện ít epidot ở mẫu KR.LK3 $(15,0 \mathrm{~m})$ bị biến đổi skarn) (Hình 13) và một lượng nhỏ khoáng vật sulfua; có thể được chia thành 2 giai đoạn phụ liên tục: (1) giai đoạn phụ hình thành quặng (giai đoạn biến chất trao đổi giật lùi sớm) và (2) giai đoạn phụ nhiệt độ thấp (giai đoạn biến chất trao đổi giật lùi muộn).

+ Giai đoạn hình thành quặng: Trong giai đoạn này, dung dịch nhiệt dịch nhiệt độ tương đối thấp và các quá trình diễn ra thủy phân, cacbonat hóa và sulfua hóa (Einaudi, 1982a, b; Meinert, 1995) làm cho các khoáng vật calc - silicat không chứa nước ở giai đoạn biến chất trao đổi tiến hóa (giai đoạn trước) được thay thế bởi tập hợp khoáng vật ngậm nước (actinolit, tremolit), oxit (magnetit), sulfua (pyrit, pyrotin và chalcopyrit) và cacbonat (canxit) chủ yếu dọc theo các khe nứt. Trong giai đoạn phụ này, clinopyroxen đã được thay thế bằng các khoáng vật actinolit, canxit và các khoáng vật không trong suốt.

Treremolit liên quan với quá trình biến chất các đá trầm tích giàu dolomit (vùng nghiên cứu đã quan sát rõ nhất ở đới xáo trộn: đá phiến thạch anh diopxit, phiến sét đen chứa thấu kính graphit, đá cacbonat chứa dolomit, các thành tạo granit, một số mạch quartzit, (Hình 14) bị dập vỡ, biến vị mạnh mẽ bởi các hệ thống đứt gãy với mặt trượt cắm theo phương $80^{\circ}$ - vết lộ KR123 (Hình 15).

Trong khu vực nghiên cứu, tremolit hóa diopxit (KR.LK1/30 (39,2 $\div 41,1 \mathrm{~m})$, kích thước của diopxit $0,2 \div 2,4 \mathrm{~mm}$. Kèm theo là các mạch canxit xuyên cắt (sinh sau) và ít hạt sphen. Tại lỗ khoan số 3, quá trình tremolit hóa rất phổ biến: vị

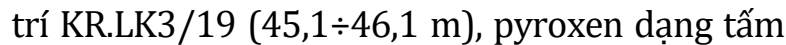
ngắn hoặc kéo dài (kích thước $0,5 \div 4 \mathrm{~mm}$ ), không màu, đa số bị carbonat hóa, tremolit hóa mạnh từng phần hoặc hoàn toàn cùng $4 \div 5 \%$ quặng. Đá hóa bị dập vỡ chứa dolomit bị tremolit hóa gặp ở

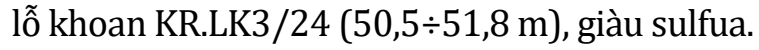

Actinolit trong giai đoạn này được thành tạo bởi sự biến đổi giật lùi của clinopyroxen (Deer và nnk., 1992):

$5 \mathrm{Ca}(\mathrm{Mg}, \mathrm{Fe}) \mathrm{Si}_{2} \mathrm{O}_{6}+\mathrm{H}_{2} \mathrm{O}+3 \mathrm{CO}_{2}=\mathrm{Ca}_{2}(\mathrm{Mg}$, $\mathrm{Fe})_{5} \mathrm{Si}_{8} \mathrm{O}_{22}(\mathrm{OH})+3 \mathrm{CaCO}_{3}+2 \mathrm{SiO}_{2}$

Sự hiện diện của các tinh thể magnetit nhỏ trong clinopyroxen cùng với actinolit, canxit, và thạch anh trong mỏ skarn chứng tỏ rằng magnetit được hình thành sau clinopyroxen trong giai đoạn biến chất trao đổi giật lùi sớm. Magnetit bị dập vỡ mạnh và các mạch nhỏ sulfua (pyrit và chalcopyrit) xuyên cắt magnetit và sự hiện diện của các tạp chất pyrit trong nó chứng tỏ rằng các sulfua hình thành muộn hơn magnetit (KR.LK3/21).

+ Giai đoạn nhiệt độ thấp: trong giai đoạn này, do dòng dung dịch nhiệt độ thấp, gồm cả khoáng 


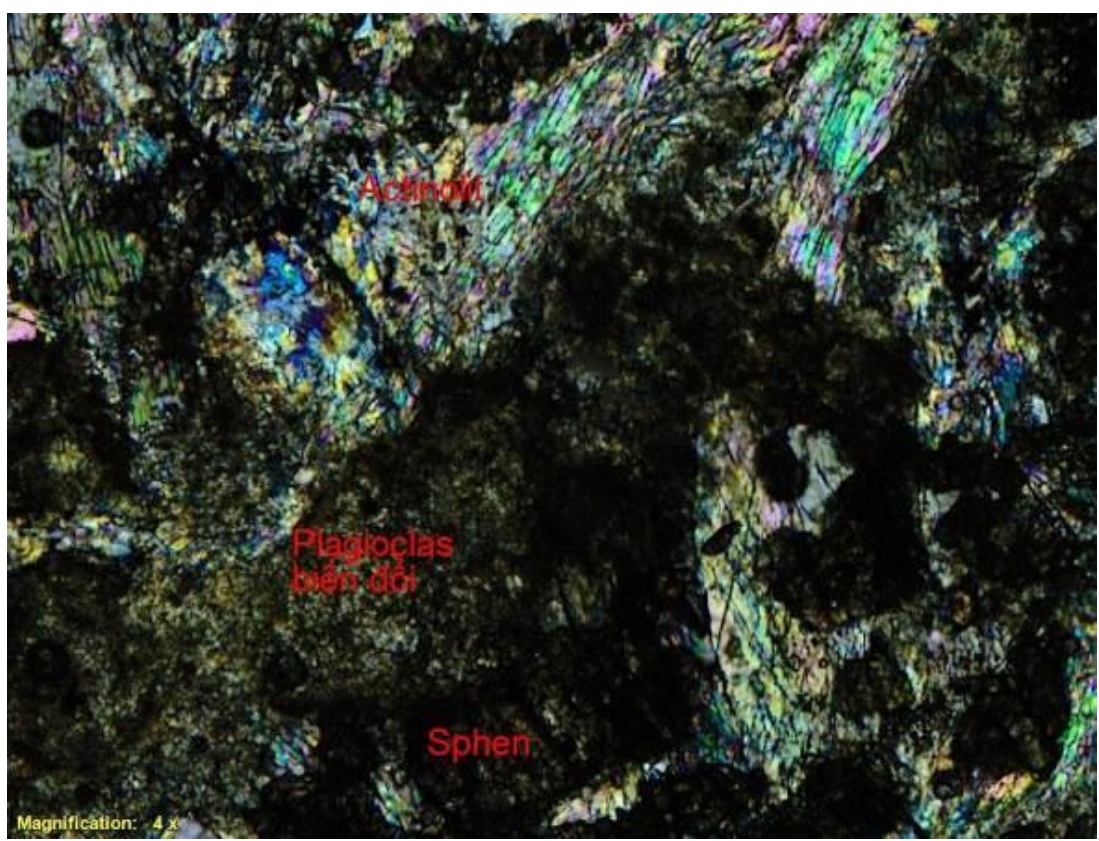

Hình 13. Các khoáng vậ ttrong đới biến đổi skarn tại LK3 ở độ sâu 15 m (2 nicon; 4x).

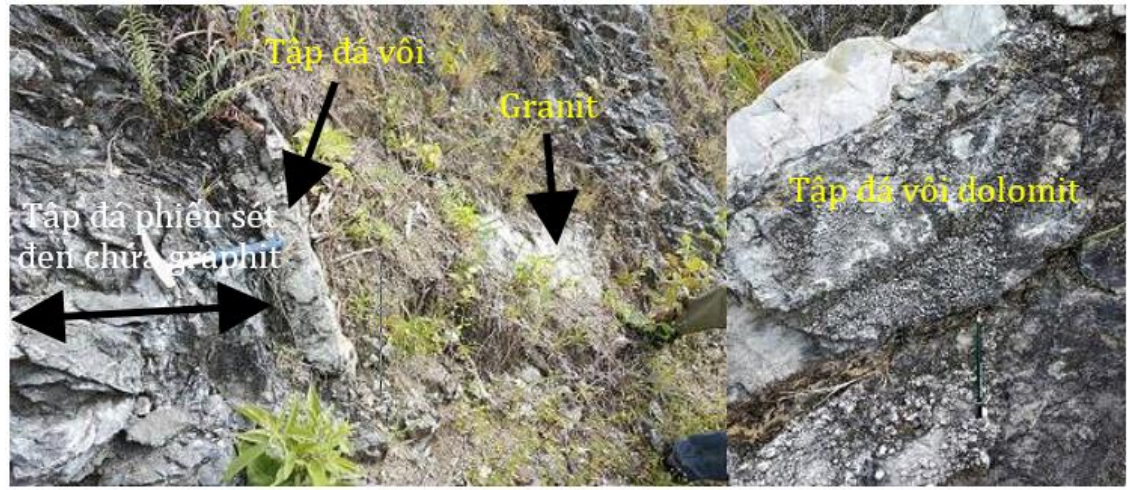

Hình 14. Đới xáo trộn dọc sông Đăk Akoi, Kon Rá.

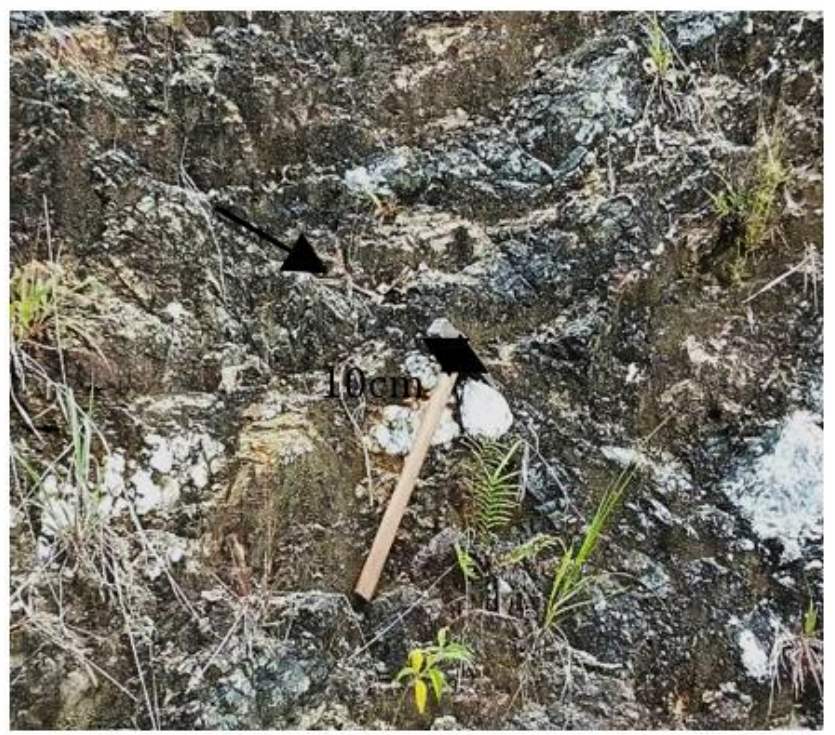

Hình 15. Đút gãy làm dịch trượt các lớp đá khoảng 10 cm tại đới xáo trộn dọc sông Đăk Akoi, Kon Rá. 
vật calc - silicat ngậm nước và không ngậm nước đã phát triển trong giai đoạn sớm hơn được thay thế bằng tập hợp hạt mịn của khoáng vật sét, chlorit, canxit, thạch anh và hematit. Ca và Singuồn gốc từ các khoáng vật vôi - silicat xuất hiện như các mạch - vi mạch thạch anh, canxit muộn.

* Có thể khái quát các quá trình biến đổi liên quan đến skarnoid của khu vực như sau: granit kiểu I tiếp xúc với các đá vôi/hoa, đá giàu Ca sẽ tạo đới skarn; tiếp xúc với đá phiến sét giàu Ca tạo nên kiểu trung gian (skarn - sừng/hornfels), kiểu này phổ biến nhất trong trường quặng Kon Rá; tiếp xúc với các đá phiến sét, phiến sét chứa graphit hình thành nên đới biến đổi chlorit hóa, dạng hạt mịn tương tự đới sừng; granit tiếp xúc với các đá cát kết, cát bột kết hình thành nên đới biến đổi quarzit (trong khu vực đã gặp các tảng lăn của quartzit khá to, hạt thô màu trắng, gần đới quặng đồng, phân bố trền vỏ phong hóa có thành phần bột, bột sét chứa sạn thạch anh ở vết lộ 111).

Theo Lu Zhang và nnk. (2018) tương ứng với kiểu skarnoid - hornfels (sừng) hay còn gọi là giai đoạn biến chất trao đổi trung gian (bimetasomatic stage) của Mir Ali Asghar Mokhtari và nnk. (2019), khu vực nghiên cứu có thể chia ra các giai đoạn như Bảng 3.

Có thể mô hình hóa kiểu mỏ Kon Rá theo cấu trúc, thạch học - khoáng vật, phân đới kim loại (Fe, $\mathrm{Cu}, \mathrm{Pb}, \mathrm{Zn}, \mathrm{Mn}, \mathrm{As}, . .$.$) , tuổi biến chất như Hình 16$. Phân đới kim loại gồm $\mathrm{Fe}, \mathrm{Cu}(\mathrm{Mo})$ tăng ở đới gần tiếp xúc, ra xa hơn là $\mathrm{As}, \mathrm{Zn}, \mathrm{Pb}, \mathrm{Mn},(\mathrm{Hg}$ ?); thành phần quặng có magnetit phân bố gần các đới nội tiếp xúc, tiến ra xa là các mạch/thân quặng sulfua (của $\mathrm{Cu}, \mathrm{Fe}, \mathrm{Mo}, \mathrm{U} ; \mathrm{Au}$ ?, HREE?) (riêng khoáng hóa của $U$, Mo gặp cả ở nội tiếp xúc trong granit pegmatit biến đổi).

Dựa vào tổ hợp đặc trưng các nguyên tố trong trường quặng đồng Kon Rá nêu trên $(\mathrm{Cu}-\mathrm{Co}-\mathrm{Ni}$, U - Mo - Ni, U - Co - Ni), chúng chỉ thị nguồn khoáng hóa thuộc nguồn nhiệt dịch sâu (nhiệt dịch magma), giai đoạn tạo khoáng khác nhau cùng môi trường tương tác magma - đá vây quanh tạo nên các tổ hợp nguyên tố kiểu chuyển tiếp như trên (có sự tham gia của nhiệt dịch hậu magma và magma muộn). Điều này phù hợp với đặc tính chuyên hóa và môi trường địa hóa của granit:

Bảng 3. Phân chia tương đối các giai đoạn biến đổi và tạo quặng liên quan với trường quặng Kon Rá (theo tài liệu thạch học, khoáng tướng, bao thể mục 3.2.1; 3.2.2; 3.2.2).

\begin{tabular}{|c|c|c|c|c|}
\hline Khoáng vật & $\begin{array}{c}\text { Giai đoạn I (Tiến } \\
\text { hóa: Progade stage) }\end{array}$ & $\begin{array}{c}\text { Giai đoạn II (Tiến hóa } \\
\text { giật lùi - Retrograde } \\
\text { stage) }\end{array}$ & $\begin{array}{c}\text { Giai đoạn III } \\
\text { (Sulfua - thạch } \\
\text { anh) } \\
\end{array}$ & $\begin{array}{c}\text { Giai đoạn IV - } \\
\text { Thứ sinh }\end{array}$ \\
\hline \multicolumn{5}{|l|}{ Dioxit } \\
\hline \multicolumn{5}{|l|}{ K - Felspat } \\
\hline \multicolumn{5}{|l|}{ Actinolit } \\
\hline \multicolumn{5}{|l|}{ Tremolit } \\
\hline \multicolumn{5}{|l|}{ Chlorit } \\
\hline \multicolumn{5}{|l|}{ Magnetit } \\
\hline \multicolumn{5}{|l|}{ Thạch anh } \\
\hline \multicolumn{5}{|l|}{ Molipdenit } \\
\hline \multicolumn{5}{|l|}{ Chalcopyrit } \\
\hline \multicolumn{5}{|l|}{ Pyrit } \\
\hline \multicolumn{5}{|l|}{ Pyrotin } \\
\hline \multicolumn{5}{|l|}{ Canxit } \\
\hline \multicolumn{5}{|l|}{ Hematit } \\
\hline \multicolumn{5}{|l|}{ Gotit } \\
\hline \multicolumn{5}{|l|}{ Covelin } \\
\hline Nhiệt độ & & $210 \div 27$ & & \\
\hline
\end{tabular}




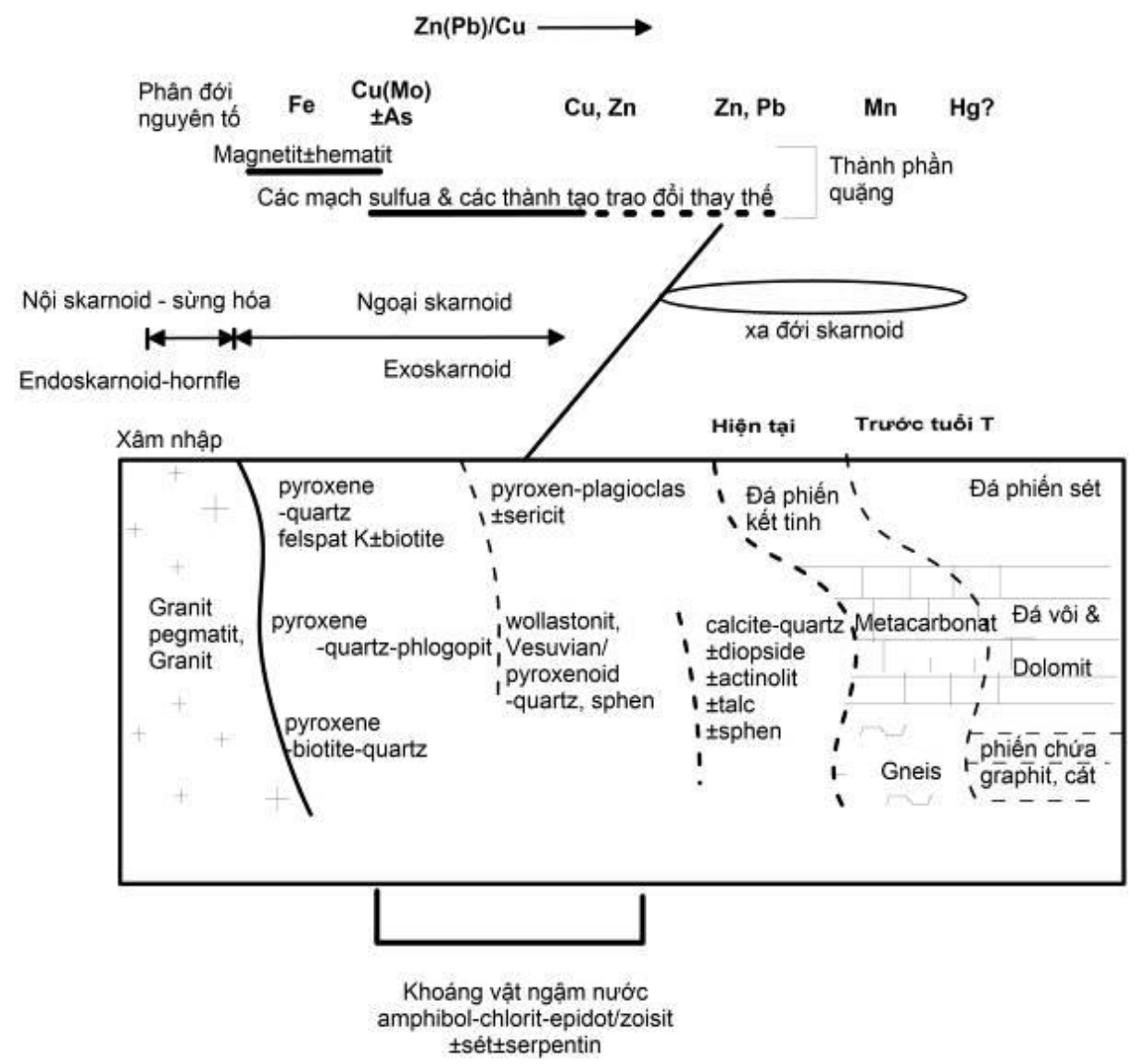

Hình 16. Mô hình cấu trúc phân đói địa hóa và đói biến đổi của kiểu mỏ skarnoid Kon Rá (Theo K. G. Mc Quen, 2005; có chỉnh sứa, bổ sung).

oxy hóa vừa - mạnh, chuyên hóa $\mathrm{Cu}$, Mo và gradient chuyên hóa thay đổi giảm dần theo hướng tăng tính oxy hóa, đảm bảo khả năng thuận lợi di chuyển các kim loại này từ dung thể magma vào dung thể quặng. Trong đó, granit hạt nhỏ và granit pegmatit có vai trò tạo quặng chính.

Đồng thời sự xuất hiện của $\mathrm{C}$ trong pyrit của quặng đồng đặc trưng cho nguồn hỗn nhiễm bởi quá trình biến chất trao đổi và tạo quặng. Hiện tượng này còn biểu thị ở tổ hợp nguyên tố cộng sinh của đới thứ sinh trong trường quặng gồm: $\mathrm{Cu}$ - $\mathrm{Fe}^{3+}-\mathrm{Mn}^{2+}-\mathrm{Zn}-\mathrm{Ca}^{2+}-\mathrm{Co}-\mathrm{P}^{5+}$.

Nhiệt độ thành tạo từ cận dưới của trung bình đến trung bình cao phù hợp với quá trình biến chất trao đổi và các giai đoạn kết tinh của dung thể magma: giai đoạn kết tinh granit pegmatit liên quan trực tiếp với tạo khoáng urani (uraninit và xạ rất cao) có thể là giai đoạn muộn nhất (magma muộn, giàu chất bốc), nhiệt độ trung bình - thấp; giai đoạn granit hạt nhỏ - vừa kết tinh sớm hơn và có khả năng sinh đồng, molipden; magnetit sẽ tập trung ở giai đoạn đầu.
Đặc điểm địa hóa nhóm nguyên tố đất hiếm cho thấy, về dạng đồ hình và tỷ số LREE/HREE giữa hai kiểu quặng khá giống nhau (loại I - thân quặng trong đới biến đổi, II - dạng mạch; Hình 11), nhưng tổng đất hiếm của quặng đồng loại I thấp hơn hẳn, có thể do tính linh động của REE, đặc biệt HREE liên quan quá trình biến chất trao đổi với các thành phần đá vây quanh giàu carbonat (Jenner, 1996). Do đó, chúng cùng nguồn nhưng giai đoạn thành tạo khác nhau. Sự dị thường dương của Ce và âm của Eu đặc trưng cho môi trường oxy hóa (Handerson, 1984) nên chúng cũng chỉ thị kiểu mỏ skarnoid oxy hóa (theo cách phân chia kiểu mỏ skarn của Lawrence và Meinert, 1997). Nó khá phù hợp với các pha khoáng vật gặp ở trường quặng Kon Rá: pyroxen diopxit, vesuvianit, wollastonit, actinolit, epidot, hematit, magetit và xuất hiện các đá vây quanh chứa dolomit cùng thành tạo với các mạch magnetit đặc xít; vesuvianit và wollastonit gần đới tiếp xúc đá hóa; epidot - actinolit liên quan với sericit hóa ở đới ngoại tiếp xúc khu vực Kon Rá đặc 
trưng cho biến đổi giật lùi.

Sự xuất hiện các thân quặng urani (LK3) và uraninit trong granit pegmatit (có thể chỉ là khoáng vật phụ trong đá granit pegmatit) ở đới nội tiếp xúc đặc trưng cho quá trình sinh quặng này thuộc giai đoạn magma muộn (Sinh sau đồng).

\section{Kết luận}

Đặc điểm địa hóa nguyên tố chính và hiếm vết trong đá gốc granit chỉ thị cho môi trường magma có tiềm năng sinh khoáng Cu và khoáng hóa liên quan magma có tính oxy hóa, kiểu I granit; gradient địa hóa rõ ràng của $\mathrm{Cu}$ và Mo trong granit: tính chuyên hóa khoáng vật phụ của $\mathrm{Cu}$ và tính chuyên hóa của Mo có sự suy giảm đáng kể từ granit hạt vừa chứa biotit sang granit hạt nhỏ sáng màu hơn. Điều này phù hợp với khả năng đưa $\mathrm{Cu}$, Mo và các nguyên tố liên quan từ dung thể magma oxy hóa vào dung thể quặng. Đồng thời, sự xuất hiện hàm lượng của $\mathrm{C}$ cao trong pyrit của quặng đồng chỉ thị cho nguồn trao đổi từ đá vây quanh,... Tính phân đới địa hóa nhóm kim loại liên quan quặng khá phù hợp với kiểu mỏ skarnoid,...

Nguồn sinh quặng và năng lượng tạo mỏ do quá trình biến chất trao đổi kiểu giữa granit tuổi trias và các đá biến chất cổ với thành phần hiện tại là đá phiến gneis biotit, metacacbonat, đôi chỗ gặp quazit (đá nguyên thủy là đá phiến, vôi và dolomit, greywack bị biến chất ở giai đoạn Trias).

Kiểu mỏ đồng Kon Rá thuộc kiểu skarnoid, thể hiện rõ nhất ở hai giai đoạn chính, gồm: i) giai đoạn biến chất trao đổi trung gian (bimetasomatic) đi kèm với phản ứng khử cacbonthường hình thành nên các khe nứt trong đá vây quanh chứa vôi tạo các khoáng vật silicat vôi không chứa nước, giàu sắt, hạt trung bình đến thô (diopxit, pyropxen); ii) giai đoạn biến chất trao đổi giật lùi (Retrograde metasomatic stage) tạo nên các khoáng vật ngậm nước (actinolit, tremolit, chlorit, trong khu vực xuất hiện ít epidot). Theo đặc tính môi trường địa hóa, kiểu mỏ này thuộc kiểu skarnoid oxy hóa, thường phát triển ở phần nông. Khoáng hóa urani hình thành ở pha muộn hơn khoáng hóa đồng.

Ngoài ra, không ngoại trừ khoáng sản đất hiếm đi kèm (đất hiếm nhóm nặng).

\section{Đóng góp của các tác giả}

Trần Duân, Nguyễn Tiến Dũng cung cấp, biên tập cơ sở dữ liệu, giúp cho triển khai thực địa, liên kết các dữ liệu phân tích trên từng đối tượng tại thực địa và so sánh với một số nghiên cứu trước đây, xây dựng sơ đồ địa chất, cấu trúc và khoáng sản liên quan; Nguyễn Văn Niệm, Mai Trọng Tú, Đỗ Đức Nguyên đã kế thừa (so sánh, chọn lọc), chỉ định bổ sung (lấy mẫu và xác định chỉ tiêu phân tích) tập mẫu địa hóa, thạch học, khoáng tướng, bao thể, địa hóa khoáng vật, kiểm tra kết quả phân tích - tổng hợp,... và luận luận giải các quá trình thành tạo mỏ, kiểu mỏ; Bùi Hữu Việt, Dương Công Hiếu, Phạm Hùng Thanh tính toán, vẽ các sơ đồ/biểu đồ, xây dựng mặt cắt, tổng hợp phần địa chất khoáng sản chung,...

\section{Tài liệu tham khảo}

Deer, W. A., Howie, R. A. and Zussman, J. (1992). An introduction to the rock - forming minerals, (2nd eds.). Longman Scientific and Technical, London, 696p.

Einaudi M. T. (1982a). General features and origin of skarns associated with porphyry copper plutons. In: Titley SR (ed) Advances in geology of porphyry copper deposits. Tucson, Southwestern North America. University of Arizona Press. 185 - 210 Arab J Geosci (2019) 12: 658 Page 21 of 23 658Einaudi MT (1982b) Descriptions of skarns associated with porphyry copper plutons. In: Titley SR (ed) Advances in geology of porphyry copper deposits. Tucson. Southwestern North America. University of Arizona Press. 1592 1606.

Henderson P. (1984). Rare earth element geochemistry. Elsevier: London, U.K.

Jenner, G. A. (1996). Trace element geochemistry of igneous rocks: geochemical nomenclature and analytical geochemistry, in Wyman, D.A., ed. Trace Element Geochemistry of Volcanic Rocks: Applications for Massive Sulphide Exploration. Geological Association of Canada, Short Course Notes, 12, 512 - 287.

McQuen, K. G. (2005). Ore deposit types and their primary expressions. In book: Regolith Expression of Australian Ore Systems (1-14). https://www.researchgate.net/publication/ 267839370. 
Lawrence D. Meinert, (1997). Application of Skarn depositzonation Model to mineral exploration. Explo. Mining Geol., 6(2), 185 - 208.

Lu Zhang, Shao - Yong Jiang, Suo - FeiXiong, and Deng - FeiDuan. (2018). Fluid Evolution of Fuzishan Skarn Cu - Mo Deposit from the Edong District in the Middle - Lower Yangtze River Metallogenic Belt of China: Evidence from Petrography, Mineral Assemblages, and Fluid Inclusions. Hindawi Geofluids, Volume 2018, Article ID 9402526, 25 pages https:// doi.org/ 10.1155/2018/9402526.

Mai Trong Tu và nnk., (2016). Discovery of uranium mineralization in Kon $\mathrm{Ra}$ by combination of georadioactive and geophysical methods. Workshop on capacity buiding on geophysical tecnology in mineral exploration and assessment on land, sea and island. Proceedings. Hanoi, Vietnam.

Meinert L. D. (1995). Compositional variation of igneous rocks associated with skarn deposits chemical evidence for a genetic connection between petrogenesis and mineralization. In: Thompson JFH (ed.) Magmas, fluids and ore deposits. Miner Assoc of Canada, Short Course Series, 23, 400 - 418.

Mir Ali Asghar Mokhtari \& Hossein Kouhestani \& Kazem Gholizadeh. (2019). Mineral chemistry and formation conditions of calc - silicate minerals of Qozlou Fe skarn deposit, Zanjan Province, NW Iran. Arabian Journal of Geosciences, 12, 658.
Nguyễn Tiến Dũng - Nguyễn Văn Niệm (Đồng tác giả), Trần Duân, Nguyễn Văn Hoàn, Đỗ Đức Nguyên, Nguyễn Đắc Sơn (2020). Hành vi địa hóa của $\mathrm{Cu}, \mathrm{U}$ và Mo trong trường quặng đồng - uran Kon Ra. Tạp chí Địa chất, loạt A, 373 $-374 / 2020$.

Nguyễn Tiến Dũng, Nguyễn Văn Niệm, Trần Duân, Đỗ Đưc Nguyen, Nguyễn Đắc Sơn, Nguyễn Văn Hoan. (2021). Nghiên cúu kiểu quặng đồng - urani trường quặng Kon Rá, Kon Tum để định hướng công tác đánh giá tiếp theo, mã: TNMT. 2018.03.11. Liên đoàn địa chat Mien Nam. Thành pho Ho Chı Minh.

Nguyễn Xuân Bao, Trịnh Văn Long, Phạm Huy Long, Vũ Như Hùng, Nguyễn Hữu Tý, Đặng Văn Rời, Đỗ Văn Lĩnh, Phạm Văn Hưng, Nguyễn Kim Hoàng, Nguyễn Văn Bỉnh, Mai Kim Vinh, Trần Xuan Toan, Nguyễn Thanh Long, Dương Văn Tam. (2000). Nghiên cúu kiến tạo và sinh khoáng Nam Việt Nam. Liên đoàn địa chat Mien Nam. Thành pho Ho Chı Minh.

Trần Duân (Chủ biên), Nguyễn Văn Bỉnh, Đỗ Ngọc Chuan, Nguyễn Văn Hai, Đinh Xuân Hoàng, Nguyễn Tat Khoa, Vũ Trong Tan, Nguyễn Năng Thanh, Nguyễn Thanh Tra, (2021). Báo cáo Đánh giá khoáng sản đồng khu vực Kon Rá, xã Đắk Tơ Lung, Huyện Kon Rẫy, Tỉnh Kon Tum. Thuôc Đe án: Lâp ban đo đia chat và đieu tra khoáng san, ty lê 1: 50.000 nhóm tờ Kon Plong, thuôc tınh Kon Tum, Gia Lai và Quang Ngãi. Liên đoàn địa chất Miền Nam. Thành pho Ho Chı Minh. 